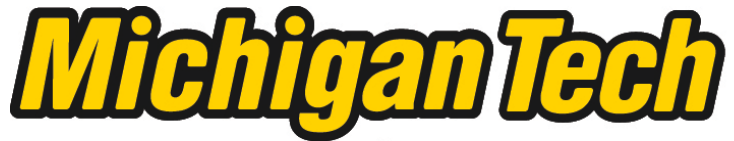 \\ Michigan Technological University Create the Future Digital Commons @ Michigan Tech
}

\section{Inhibition of L-type amino acid transport with non-physiological amino acids in the Pahenu2 mouse model of phenylketonuria}

Kara R. Vogel

Michigan Technological University

Follow this and additional works at: https://digitalcommons.mtu.edu/etds

Part of the Biology Commons

Copyright 2012 Kara R. Vogel

\section{Recommended Citation}

Vogel, Kara R., "Inhibition of L-type amino acid transport with non-physiological amino acids in the Pahenu2 mouse model of phenylketonuria", Master's Thesis, Michigan Technological University, 2012.

https://doi.org/10.37099/mtu.dc.etds/193

Follow this and additional works at: https://digitalcommons.mtu.edu/etds

Part of the Biology Commons 
INHIBITION OF L-TYPE AMINO ACID TRANSPORT WITH NONPHYSIOLOGICAL AMINO ACIDS IN THE $\mathrm{Pah}^{\text {enu2 }}$ MOUSE MODEL OF PHENYLKETONURIA

\author{
By \\ Kara R. Vogel \\ A THESIS \\ Submitted in partial fulfillment of the requirements for the degree of \\ MASTER OF SCIENCE \\ (Biological Sciences) \\ MICHIGAN TECHNOLOGICAL UNIVERSITY \\ 2012
}

(C) 2012 Kara R. Vogel 
This thesis, "Inhibition of L-Type Amino Acid Transport with Non-Physiological Amino Acids in the Pah ${ }^{\text {enu2 }}$ Mouse Model of Phenylketonuria," is hereby approved in partial fulfillment of the requirements for the Degree of MASTER OF SCIENCE IN BIOLOGICAL SCIENCES.

Department of Biological Sciences

Signatures:

Thesis Advisor

Dr. K. Michael Gibson

Committee Member

Dr. Thomas Werner

Committee Member

Dr. Ashutosh Tiwari

Department Chair

Dr. K. Michael Gibson

Date 
Dedication

To my Beautifuls. 


\section{Table of Contents}

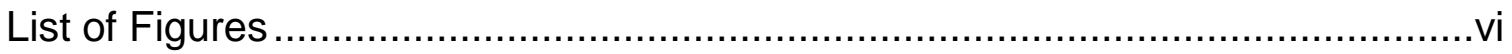

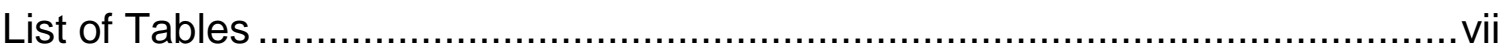

Acknowledgements .............................................................................ii

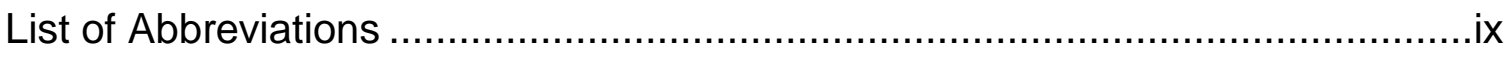

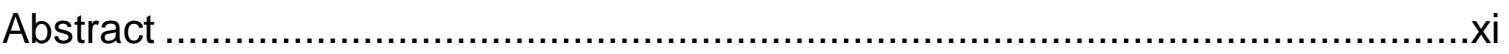

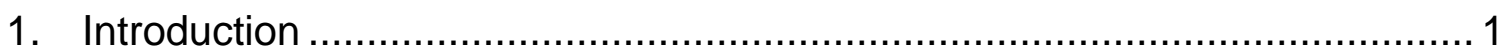

1.1. Phenylketonuria

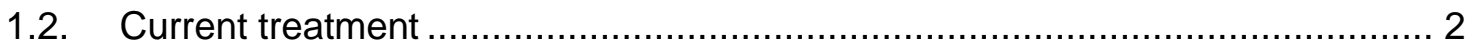

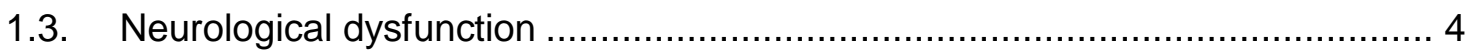

1.4. L-type amino acid transporter, LAT1 ...................................................... 4

1.5. Non-physiological amino acids, NPAAs ...................................................... 8

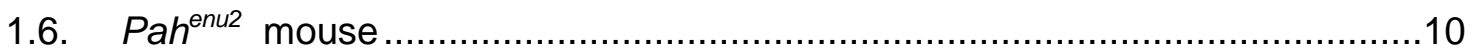

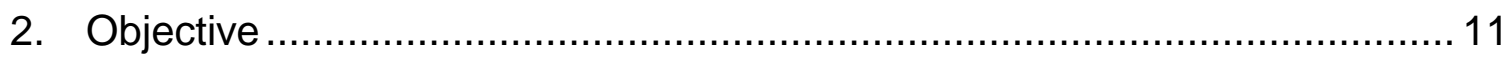

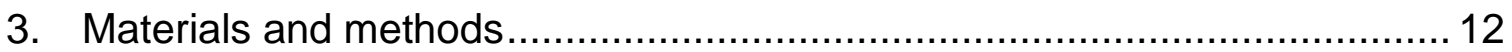

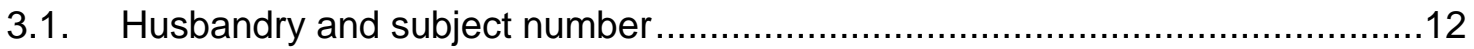

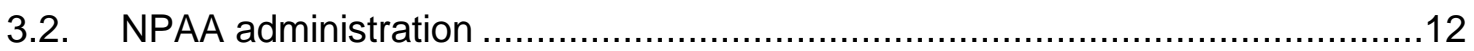

3.3. High performance liquid chromatography, HPLC ......................................13

3.4. Liquid chromatography tandem mass spectrometry …...............................13

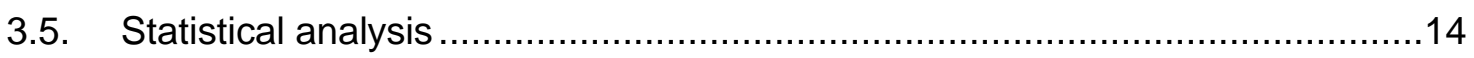

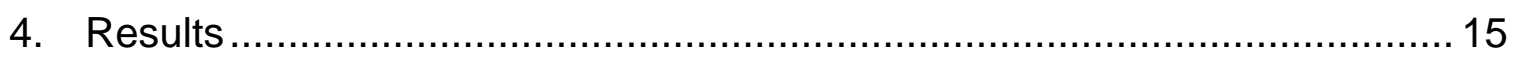

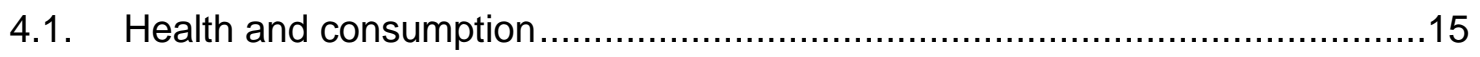

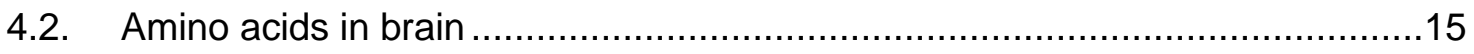

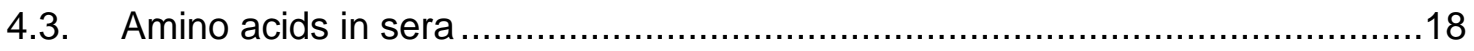

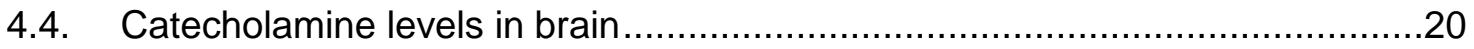

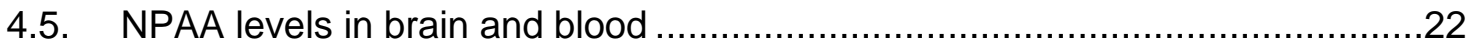


4.6. Effect of NL feeding on blood chemistries.......

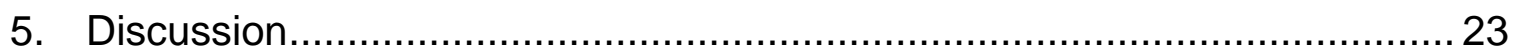

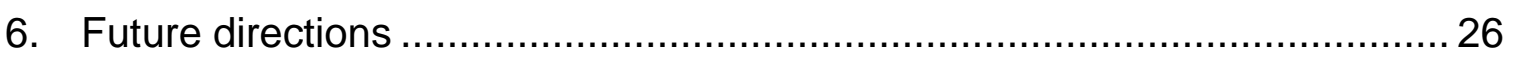

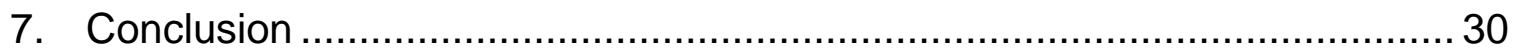

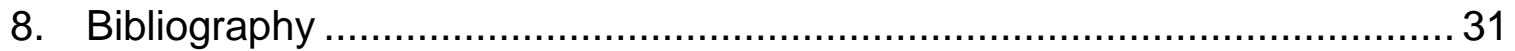




\section{List of Figures}

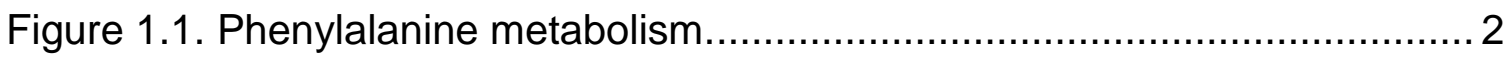

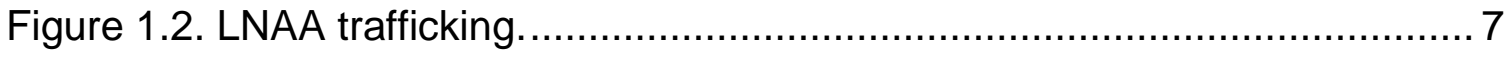

Figure 1.3. Dopamine (DA) and Serotonin (5-HT) synthesis and metabolism ...... 7

Figure 1.4. Non-physiological amino acids ................................................. 9

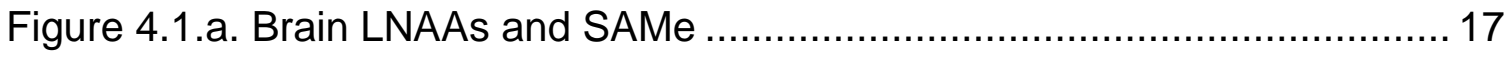

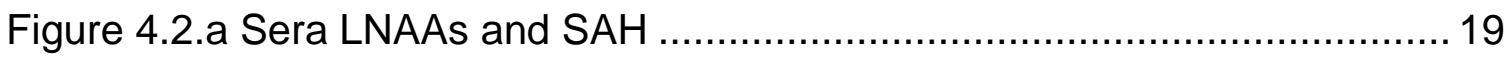

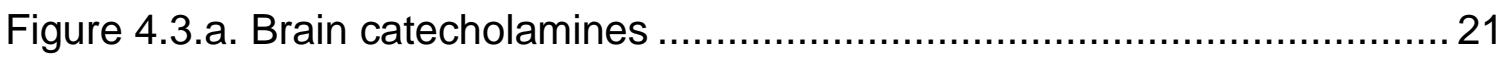

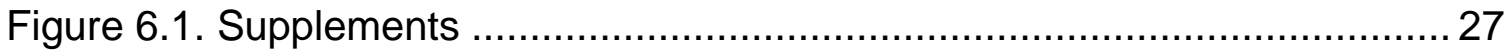

Figure 6.2. Open field testing paradigm ...................................................... 29 


\section{List of Tables}

Table 1.1. System L-type amino acid transporters ........................................ 5

Table 4.1. Consumption and weight ........................................................ 15

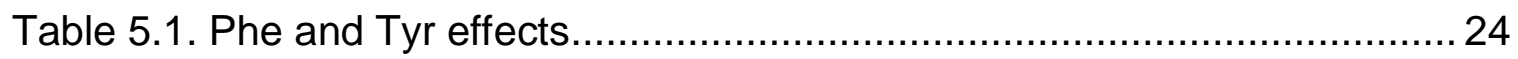

Table 6.1. NPAA supplements............................................................... 27 


\section{Acknowledgements}

Thank you very much to my advisor K. Michael Gibson, Ph.D., who I admire and respect. I am very lucky for the opportunity to know and to learn from you- not enough can be said. Thank you very much to my committee members, Thomas Werner, Ph.D. and Ashutosh Tiwari, Ph.D; I am grateful to have your intellectual contribution to my project. I don't know that I could have survived it all without such a great mentor and friend as Dr. Werner. Thank you for allowing me to use your imager, microscope, for all the homemade taq polymerase, and for your continuous help and evaluation of my writing and presentation skills. Thank you so much to our collaborators in this work Teodoro Bottiglieri, Ph.D., Brandi Wasek and Erland Arning for running my samples and for training me in analytical chemistry and regional brain dissections. I had a lovely time in Dallas. Thank you to Jonathan Gruber, Ph.D. for teaching me laboratory technique, etc. Thank you to David Talaga II for help weighing animals and making chow.

Thank you to the Gibson laboratory members Matt Helgen, Andrew Kennedy, Aparna Deshpande, and Faith Lambert.

Partial support for these studies was obtained from NIH HD 58553 and a grant from the National PKU Alliance (NPKUA), which is gratefully acknowledged. 


\section{List of Abbreviations}

3-MT 3- methoxytyramine

5-HIAA 5-hydroxyindoleacetic acid

5-HT serotonin

5-HTP 5-hydroxytryptophan

AA amino acids

AIB aminoisobutyric acid

ASCT alanine-serine-cysteine transporter

BBB blood brain barrier

BCAA branched-chain amino acid

$\mathrm{BH}_{4} \quad$ tetrahydrobiopterin

CNS central nervous system

Cys; C cysteine

DA dopamine

DOPAC 3,4-dihydroxyphenylacetic acid

Glu; E glutamate

GIn; Q glutamine

His; $\mathbf{H} \quad$ histidine

HMGCR 3-hydroxy-3-methyl-glutaryl-CoA reductase

HVA homovanillic acid

Ile; I isoleucine

L-DOPA L-dihydroxyphenylalanine

LAT1 L-type amino acid transporter

Leu; $\mathbf{L} \quad$ leucine 


$\begin{array}{ll}\text { LNAA } & \text { large neutral amino acid } \\ \text { NL } & \text { DL-norleucine } \\ \text { MAIB } & \text { methyl-aminoisobutyric acid } \\ \text { Met; M } & \text { methionine } \\ \text { MRI } & \text { magnetic resonance imaging } \\ \text { MRS } & \text { magnetic resonance spectroscopy } \\ \text { MSUD } & \text { maple syrup urine disease } \\ \text { NB } & \text { 2-aminobicyclo(2,2,1)heptane-2-carboxylic acid; } \\ & \text { 2-aminonorbornane }\end{array}$

$\begin{array}{ll}\text { NPAA } & \text { non-physiological amino acid } \\ \text { NTBC } & \text { nitisinone }\end{array}$

PAH phenylalanine hydroxylase

Phe; F phenylalanine

PKU phenylketonuria

SAMe S-adenosylmethionine

Ser; $\mathbf{S} \quad$ serine

SAT system A transporter

Thr; T threonine

Trp; W tryptophan

Tyr; Y tyrosine

Val; V valine 


\section{Abstract}

Phenylketonuria, an autosomal recessive Mendelian disorder, is one of the most common inborn errors of metabolism. Although currently treated by diet, many suboptimal outcomes occur for patients. Neuropathological outcomes include cognitive loss, white matter abnormalities, and hypo- or demyelination, resulting from high concentrations and/or fluctuating levels of phenylalanine. High phenylalanine can also result in competitive exclusion of other large neutral amino acids from the brain, including tyrosine and tryptophan (essential precursors of dopamine and serotonin). This competition occurs at the blood brain barrier, where the L-type amino acid transporter, LAT1, selectively facilitates entry of large neutral amino acids. The hypothesis of these studies is that certain non-physiological amino acids (NPAA; DL-norleucine (NL), 2aminonorbornane (NB; 2-aminobicyclo-(2,1,1)-heptane-2-carboxylic acid), $\alpha$ aminoisobutyrate (AIB), and a-methyl-aminoisobutyrate (MAIB)) would competitively inhibit LAT1 transport of phenylalanine (Phe) at the blood-brain barrier interface. To test this hypothesis, $\mathrm{Pah}^{-/}$mice $\left(\mathrm{n}=5\right.$, mixed gender; $\mathrm{Pah}^{+/-}$ $(n=5)$ as controls) were fed either $5 \% \mathrm{NL}, 0.5 \% \mathrm{NB}, 5 \%$ AIB or $3 \%$ MAIB (w/w $18 \%$ protein mouse chow) for 3 weeks. Outcome measurements included food intake, body weight, brain LNAAs, and brain monoamines measured via LCMS/MS or HPLC. Brain Phe values at sacrifice were significantly reduced for NL, $\mathrm{NB}$, and MAIB, verifying the hypothesis that these NPAAs could inhibit Phe trafficking into the brain. However, concomitant reductions in tyrosine and methionine occurred at the concentrations employed. Blood Phe levels were not altered indicating no effect of NPAA competitors in the gut. Brain NL and NB levels, measured with HPLC, verified both uptake and transport of NPAAs. Although believed predominantly unmetabolized, NL feeding significantly increased blood urea nitrogen. $\mathrm{Pah}^{-/}$disturbances of monoamine metabolism were exacerbated by NPAA intervention, primarily with NB (the prototypical LAT inhibitor). To achieve the overarching goal of using NPAAs to stabilize Phe transport levels into the brain, a specific Phe-reducing combination and concentration of NPAAs must be found.

Our studies represent the first in vivo use of NL, NB and MAIB in $\mathrm{Pah}^{-/}$mice, and provide proof-of-principle for further characterization of these LAT inhibitors. Our data is the first to document an effect of MAIB, a specific system A transport inhibitor, on large neutral amino acid transport. 


\section{Introduction}

\subsection{Phenylketonuria}

Phenylketonuria $(\mathrm{PKU})$ is an autosomal recessive disorder, which affects more individuals than any other inherited disorder of amino acid metabolism (U.S. frequency $1: 15,000$ ). The disease was first discovered by Asbjorn Følling in 1934, who recorded high levels of phenylpyruvic acid (keto-phenylpyruvate) in the urine of two mentally impaired siblings (Følling 1994). In PKU, the deficiency of phenylalanine hydroxylase, $P A H$, leads to pathological levels of phenylalanine (Phe) in the brain and blood, normal to low levels of tyrosine (Tyr), and increased side-chain conversion of Phe to downstream organic acid metabolites. The enzyme $P A H$ is responsible for the stereospecific, irreversible hydroxylation of $\mathrm{L}$ Phe to the non-essential amino acid tyrosine (Fig. 1.1; Pavon et al. 2006). The enzyme assembles into a homotetramer forming a $165 \mathrm{kDa}$ multimer of three domains: regulatory, catalytic and tetramerization domains. Divalent iron $\left(\mathrm{Fe}^{2+}\right)$ binds the catalytic domain of the enzyme to achieve full activity, and phosphorylation at serine 16 of the regulatory domain alters the conformation of the active site between open and closed forms (Richardson et al. 1993; Kaufman 1986). $P A H$ catalysis requires the cofactor tetrahydrobiopterin $\left(\mathrm{BH}_{4}\right)$, which can exhibit pathway mutations in anabolic or recycling enzymes involved in its formation, which leads to a milder form of hyperphenylalanemia. The genomic location of $P A H$ maps to the $12^{\text {th }}$ chromosome, region $12 \mathrm{q} 22-12 \mathrm{q} 24.1$ in $H$. sapiens, and contains 13 exons (Lidsky et al. 1985). There are more than 500 disease-causing mutations of the $P A H$ gene reported on the $P A H$ locus database, which present varying degrees of disease phenotype (Williams et al. 2008). PKU is characterized by cognitive loss, white matter abnormalities, hypoor demyelination of neuronal axons, and seizures caused by pathological phenylalanine levels. Severe and irreversible mental retardation results in cases of untreated classical PKU (classical PKU characterized by blood Phe levels $>1,200 \mu \mathrm{mol} / \mathrm{L}$, hyperphenylalaninaemia or mild PKU Phe levels $>600$ and $<1,200 \mu \mathrm{mol} / \mathrm{L})$ (Lutz et al. 1982; Lutz et al. 1990). 


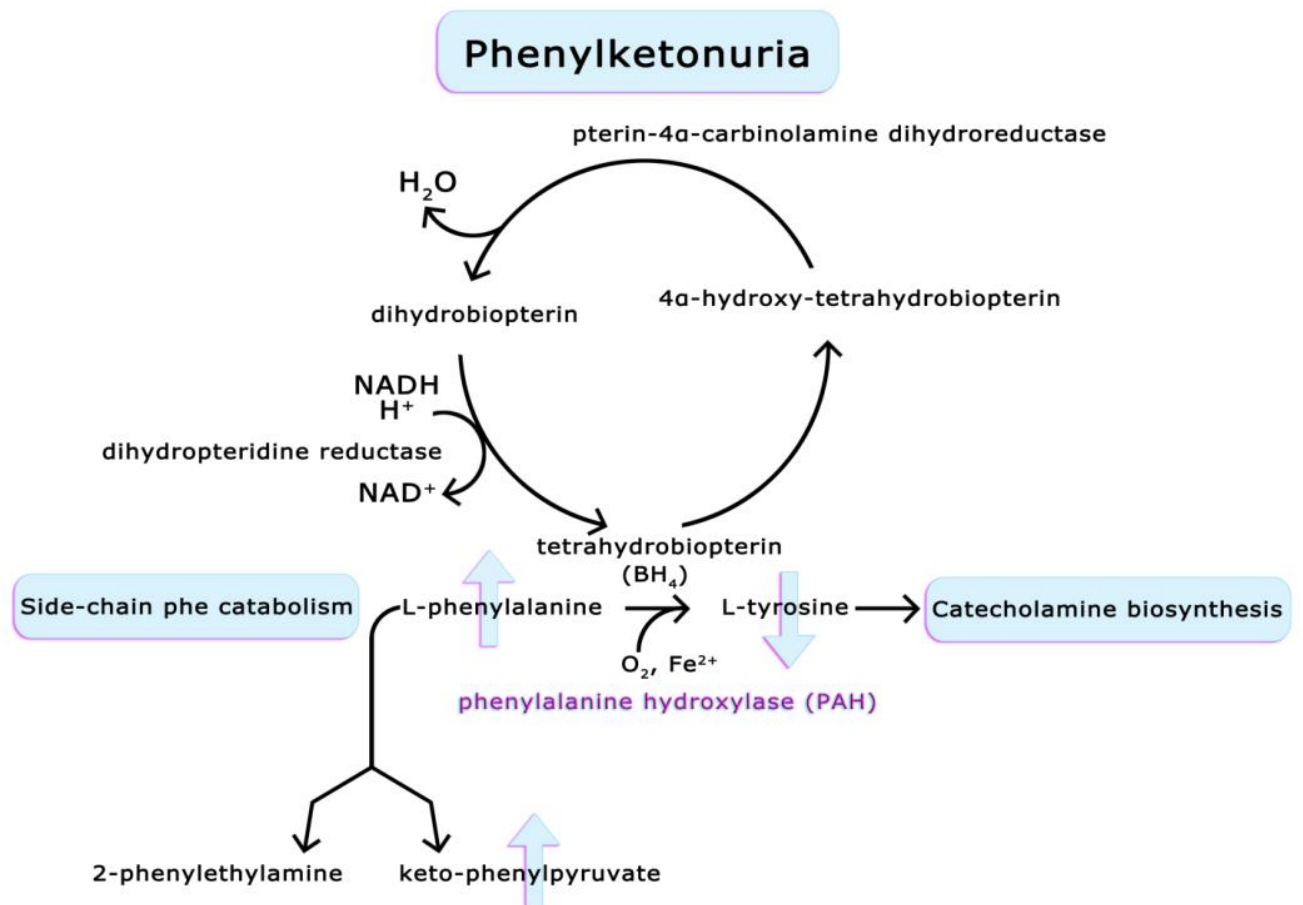

Figure 1.1. Phenylalanine metabolism in mammals and the block in phenylketonuria. Hyperphenylalaninemia results from mutations in the $P A H$ gene $(99 \%$ of disease causing mutations) and enzymes responsible for $\mathrm{BH}_{4}$ synthesis and recycling (Erlandsen et al. 1999). Phenylalanine hydroxylation to tyrosine is blocked, and phenylalanine undergoes side-chain conversion to keto-phenylpyruvate.

\subsection{Current treatment}

PKU patients are required to adhere to a protein-restricted diet, avoid foods high in phenylalanine content, and maintain lifelong dietary control. However, in the meta-analysis by Enns et al. 2010, dietary treatment alone resulted in suboptimal outcomes for neurocognitive, psychosocial and nutritional factors in PKU patients. Intellectual quotient and executive function were compromised in earlytreated adolescents exhibiting blood Phe variability within the recommended levels (target blood Phe 120-360 $\mu \mathrm{mol} / \mathrm{L}$; (NIH Consensus 2001). Thus, metabolic fluctuations in Phe, or associated metabolites, appear to correlate with cognitive development of PKU patients even in the case of dietary adherence (NIH Consensus 2001; Enns et al. 2010). Some current research approaches to the treatment of hyperphenylalanemia seek to stabilize Phe levels through enzyme replacement therapy, cellular transplantation, or gene therapy. Polyethylene glycolated (PEG) phenylalanine ammonium lyase (PAL), which converts phenylalanine to the byproduct trans-cinnamate, has already progressed to 
clinical trials. However, the question of affordability and the feasibility of reaching the larger PKU population with enzyme replacement remain to be determined. A pharmacological approach to treatment with the drug sapropterin (Kuvan, BioMarin Corp.) has shown efficacy in the treatment of $\mathrm{BH}_{4}$-responsive $\mathrm{PKU}$ (Muntau et al. 2002). Sapropterin therapy, as an alternative to dietary intervention alone, costs approximately $\$ 100,000$ and $\$ 150,000$ annually (estimate for the highest dosage of $20 \mathrm{mg} / \mathrm{kg} / \mathrm{day}$; (Harding 2010). New dietary sources of protein isolated during cheese manufacturing have been shown to reduce brain and blood phenylalanine. Glycomacropeptide, isolated from cheese whey, contains little or no phenylalanine, and a high threonine content (Ney et al. 2008), which may reduce intestinal absorption and transport of Phe into the blood. LNAA supplementation has been shown to improve levels of Phe in the blood, but this had limited efficacy for patients already adherent to a Phe restricted medical diet (Schindeler et al. 2007), and may result in negative nitrogen balance (Dotremont et al. 1995a). Maintaining nutrient balance on a natural protein-restricted diet remains a challenge (Dokoupil et al. 2011), and non-adherence can result in cognitive declines, lethargy, depression, and problems with concentration. PKU patients sometimes require individualized dietary regimes.

Dietary adherent PKU patients experience suboptimal outcomes from dietary treatment alone resulting from fluctuating Phe levels (Anastasoaie et al. 2008), deficiency of certain vitamins and minerals (calcium, folate, thiamine, niacin, and vitamin $\mathrm{B}_{6}$ intake may be up to $60 \%$ below daily recommended intake levels (Koura et al. 2011), important long chain fatty acids (eg. docosahexanoic acid; (van Gool et al. 2000), and antioxidants. Some PKU patients require vitamin B6 and B12 supplementation (Hvas et al. 2006), and accompanying deficiency in folate can lead to moderate hyperhomocysteinaemia (Schulpis et al. 2002). Increased circulating homocysteine is a risk factor for coronary artery disease (CAD); folate supplementation is suggested for high-risk CAD patients as strong correlation between low folate and high homocysteine levels has been suggested (Lee et al. 2003). Additionally, PKU patients have altered trace metal consumption including decreased selenium and zinc (Barretto et al. 2008), and increased iron and copper (Reilly et al. 1990). Selenium is a trace metal required for selenoenzyme antioxidant species GPx 1 and 3-6, which protects cells from reactive nitrogen and oxygen species (Tinggi 2008). Low levels of ubiquinone coQ10 (Colomé et al. 2003) and other lipophilic antioxidants may be responsible for observed higher lipid peroxidation seen in some PKU patients. Carnitine and selenium supplementation in the diet of PKU patients for six months reverted oxidative damage and lipid peroxidation, normalized glutathione peroxidase activity, and revealed an inverse correlation between oxidative damage and carnitine levels (Sitta et al. 2011). Whereas the brain is particularly sensitive to oxidative damage, and PKU patients remain at a high risk for brain pathology, it is important to prevent a pro-oxidant environment in order to reduce the risk of 
neurological damage. PKU patients can still develop white matter lesions, as detected with magnetic resonance imaging (MRI), even with early detection and dietary treatment (Huttenlocher 2000).

\subsection{Neurological dysfunction}

Obligate heterozygous mothers of PKU patients can regulate Phe levels for their developing fetus in utero. At birth, Phe levels increase rapidly. If left unregulated, microcephaly, mental retardation, motor and behavioral disturbances may ensue. The predominant pathology of hyperphenylalanemia occurs in the central nervous system (CNS), especially white matter in the deep and subcortical regions of the brain (Anderson et al. 2010). White matter of the central nervous system is composed of the white fatty substance myelin, composed of millions of myelinated axons, which are responsible for signal transmission. Neuropathological features in the CNS of untreated PKU include: hypomyelination or demyelination, lesions, reactive astrogliosis, and reduced Purkinje (GABAergic neurons) cell dendritic arborization (Dyer 1999). The pathogenesis of PKU, although not completely understood (de Groot et al. 2010), at a minimum, results from the consequences of abnormally high blood and cerebral phenylalanine and downstream effects on the transport of other large neutral amino acids, LNAA (Fig. 1.2).

The importance of the blood brain barrier (BBB) in the biochemical regulation of LNAAs has been implicated in the neuropathology of the disease by magnetic resonance spectroscopy (MRS), which permits in vivo cerebral Phe measurements. MRS studies enable correlation between cerebral levels of Phe and the degree of cognitive impairment and growth in patients (van Spronsen et al. 2009). Studies by Anderson et al. correlated concurrent and lifetime Phe to white matter abnormalities (based on the median Phe level over 12 months, $r^{2}=$ 0.61 (Anderson et al. 2007; Anderson et al. 2010). High Phe levels have also been shown to inhibit selected enzymes, including tyrosine and tryptophan hydroxylases, 3-hydroxy-3-methyl-glutaryl-CoA reductase (HMGCR; Shefer et al. 2000a), and pyruvate kinase.

Current treatment strategies for PKU are targeted to curtail Phe accumulation in the blood and brain and its associated pathomechanisms. Among various systems of amino acid transporters identified (system A transporter (SAT), ASCT, $\mathrm{y}^{+}, \mathrm{x}_{\mathrm{c}}^{-}$, and $\mathrm{b}^{0,+}$; see Fig. 1.5), transport of Phe and other LNAAs takes place via a system of L-type amino acid transporters (Babu et al. 2003).

\subsection{L-type amino acid transporter, LAT1}

Four mammalian LATs (1-4) comprise the system of transporters in mammals responsible for the movement of LNAAs. System $L$ transporters are $\mathrm{Na}^{+}$and $\mathrm{Cl}^{-}$ 
independent, heterodimeric, transmembrane proteins responsible for the basolateral movement of amino acids. Functional expression requires association with the type II glycoprotein 4F2 heavy chain, 4F2hc/CD98 (Rossier et al. 1999). The two distinct genes corresponding to the heavy and light chain (LAT1) units are the solute carrier SLC2A2 and SLC7A5, respectively (Verrey et al. 2004). LATs are expressed with varying tissue specificity and substrate affinity (Table 1.1). Phenylalanine and eight other LNAAs traverse the BBB with high affinity $\left(\mathrm{K}_{\mathrm{m}}=12\right.$ to $50 \mu \mathrm{M}$, His, Phe, Leu, Met, Trp, Ile, Tyr, Val; Gln with 2 orders of magnitude lower affinity $\mathrm{Km}=1.6 \mathrm{mM}$ ) via LAT1 facilitated amino acid exchange (Fig. 1.2, Table 1.1). LAT1 has widely expressed mRNA levels. LAT2 exhibits broad LNAA usage and high affinity $\left(\mathrm{K}_{\mathrm{m}}=30\right.$ to $\left.50 \mu \mathrm{M}\right)$ for Tyr, Phe, Trp, Thr, Asn, Ile, Cys, Ser, Leu, Val, and Gln), lower affinity (180 to $300 \mu \mathrm{M})$ for His, Ala, Met, and Gly, and is primarily expressed in the small intestine, kidney, brain and placenta (Segawa et al. 1999). The affinity of LAT1-4 for LNAAs is high in comparison to blood concentrations ( $K_{m}$ value $\left.<200 \mu \mathrm{M}\right)$ guaranteeing their saturation at normophysiological blood amino acid levels. LAT1 and LAT2 (the latter an isoform of LAT1) are both expressed in the brain and facilitate tissue uptake from the blood capillaries; system $L$ is crucial to cellular homeostasis and transport of neutral amino acids.

Table 1.1.

System L-type amino acid transporters

\begin{tabular}{|c|c|c|c|c|}
\hline Transporter & $\begin{array}{l}\text { Tissue } \\
\text { Expression }\end{array}$ & $\begin{array}{l}\text { Amino Acid } \\
\text { Selectivity }\end{array}$ & $\begin{array}{l}\text { Selected } \\
\mathrm{K}_{\mathrm{m}} \mathrm{S}(\mu \mathrm{M})\end{array}$ & Citations \\
\hline LAT-1 & $\begin{array}{l}\text { Brain, } \\
\text { spleen, } \\
\text { placenta, } \\
\text { testis, fetal } \\
\text { liver }\end{array}$ & $\begin{array}{l}\text { Large neutrals: } \\
F, Y, W, M, H, L, I, V\end{array}$ & $\begin{array}{l}\text { Phe } 14 \\
\text { Leu } 20 \\
\text { Tyr 28 } \\
\text { Trp 21 } \\
\text { Met } 20 \\
\text { His } 12\end{array}$ & $\begin{array}{l}\text { (Kanai et } \\
\text { al. 1998) } \\
\text { (Yanagida } \\
\text { et al. } \\
\text { 2001) }\end{array}$ \\
\hline LAT-2 & $\begin{array}{l}\text { Brain, } \\
\text { small } \\
\text { intestine, } \\
\text { kidney, } \\
\text { placenta }\end{array}$ & $\begin{array}{l}\text { Large and small } \\
\text { neutrals: } \\
\text { F,Y,W,L,I,V,T,N,C,S,Q } \\
(\mathrm{M}, \mathrm{H}, \mathrm{G}, \mathrm{A})\end{array}$ & $\begin{array}{l}\text { Phe } 45 \\
\text { Leu } 119 \\
\text { Tyr } 36 \\
\text { Trp } 58 \\
\text { Met } 204 \\
\text { His } 181\end{array}$ & $\begin{array}{l}\text { (Segawa } \\
\text { et al. } \\
1999)\end{array}$ \\
\hline LAT-3 & $\begin{array}{l}\text { Liver, } \\
\text { pancreas, } \\
\text { skeletal } \\
\text { muscle }\end{array}$ & $\begin{array}{l}\text { Amino acids (and } \\
\text { amino acid alcohols): } \\
\text { F,L,I,V }\end{array}$ & $\begin{array}{l}\text { Phe } 6^{*} \\
\text { Leu } 8^{*}\end{array}$ & $\begin{array}{l}\text { (Babu et } \\
\text { al. 2003) }\end{array}$ \\
\hline
\end{tabular}


Table 1.1 (continued)

\begin{tabular}{|l|l|l|l|l|}
\hline Transporter & $\begin{array}{l}\text { Tissue } \\
\text { Expression }\end{array}$ & $\begin{array}{l}\text { Amino Acid } \\
\text { Selectivity }\end{array}$ & $\begin{array}{l}\text { Selected } \\
\mathrm{K}_{\mathrm{m}}(\mu \mathrm{M})\end{array}$ & Citations \\
\hline LAT-4 & $\begin{array}{l}\text { Kidney, } \\
\text { placenta, } \\
\text { leukocytes }\end{array}$ & $\begin{array}{l}\text { Large neutrals: } \\
\text { F,L,I,M }\end{array}$ & $\begin{array}{l}\text { Phe 178* } \\
\text { Leu 103* }\end{array}$ & $\begin{array}{l}\text { (Bodoy et } \\
\text { al. 2005) }\end{array}$ \\
\hline
\end{tabular}

Mammalian LATs: Tissues in which the transporters are expressed, amino acids transported by each LAT, and the affinity of the transporter for selected amino acids are summarized. LAT2 is an isoform of LAT1, and LAT4 is an isoform of LAT3. The lower affinity amino acids transported by LAT2 are shown in parentheses. LAT3 and LAT4 have both high and low affinity forms (regulated by phosphorylation). *High affinity $\mathrm{K}_{\mathrm{m}}$ listed for LAT3 and LAT4. $\mathrm{K}_{m}$ describes the concentration at half-maximal velocity in the absence of competitors (measured in Xenopus oocytes).

Supraphysiological levels of Phe in PKU are predicted to saturate the LAT transporters and competitively exclude other LNAAs from transport. Cerebral protein synthesis is dependent upon concentrations of essential amino acids (Nishihira et al. 1993), normal transport and metabolic machinery, and multiple other functions critical for brain development. Transport inhibition of LNAAs during hyperphenylalaninemia may influence the following: reduced cerebral protein synthesis due to abnormal LNAA homeostasis, neurotransmitter synthesis (dopamine, serotonin), and proteins necessary for axonal myelination, such as myelin basic protein (MBP) (Antoshechkin et al. 1991; Shefer et al. 2000b; Joachim Pietz et al. 2003; Hörster et al. 2006; Ogawa et al. 2006).

Transport competition during hyperphenylalaninemia occurs at the blood brain barrier and gut endothelium, where the large neutral amino acid transporters selectively bind and transport amino acids transcellularly. The Michaelis-Menten constant $\left(\mathrm{K}_{\mathrm{m}}\right)$ for LAT1, defined as the $1 / 2$ maximal transport saturation, represents the affinity of the LAT1 system for amino acid transport. Phe is transported with high affinity on all four LATs. LAT1 has a $\mathrm{K}_{m}$ for phenylalanine of $11 \mu \mathrm{mol} / \mathrm{L}$ (measured in rat brain in situ), and with blood phenylalanine levels in classical phenylketonuria fluctuating at or above 1,200 $\mu \mathrm{mol} / \mathrm{L}$, Phe can easily oversaturate the LAT system and exclude other LNAAs through mass action alone (Fig. 1.2; Kanai et al. 1998). Certain non-physiological amino acids, NPAAs, have proven effective at competing with Phe for LAT1 transport. 


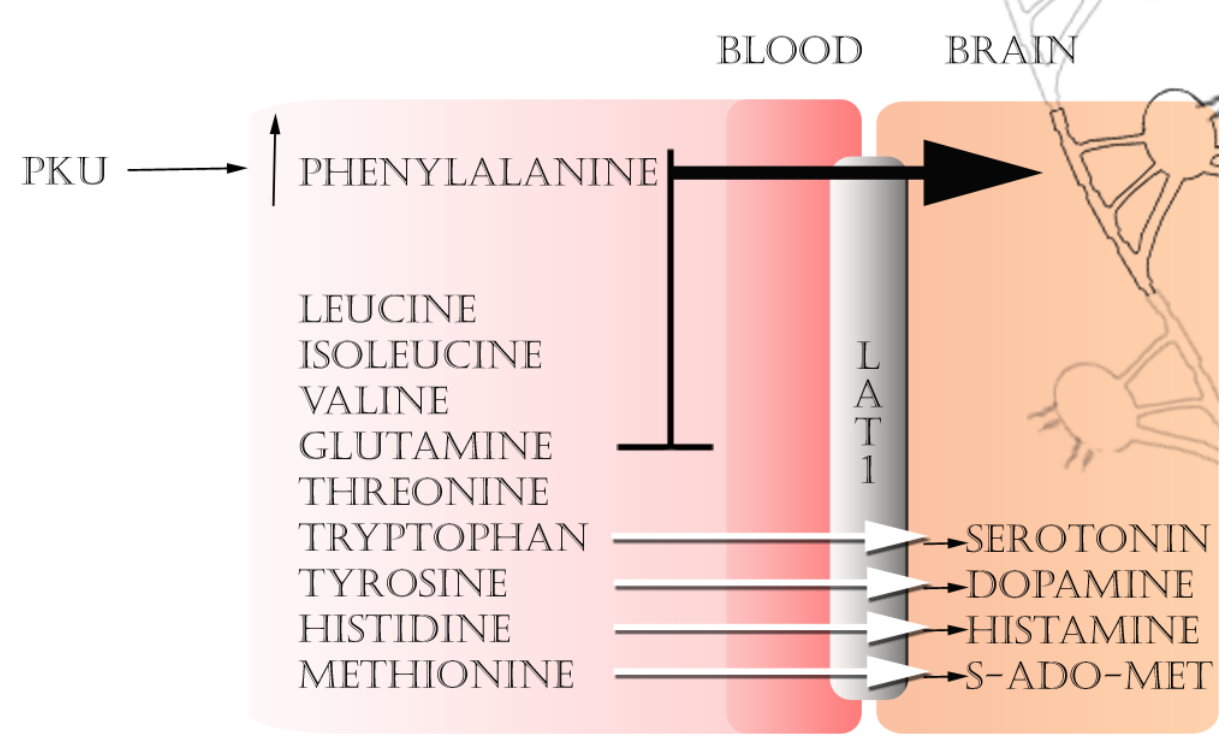

Figure 1.2. LNAA trafficking on LAT1 in PKU: Schematic diagram of the LAT1 transporter at the blood brain barrier. Accumulation of supraphysiological levels of amino acids in PKU are shown with downstream outcomes related to disrupted LAT1 transport: monoamine neurotransmitters (serotonin, dopamine), the brain's primary methyl donor, $S$-adenosylmethionine, and histamine. High levels of phenylalanine and leucine, respectively, contribute to depletion of histidine, methionine, tryptophan (Trp), and tyrosine (Tyr) in the brain due to competitive exclusion via LAT1 oversaturation at the blood brain barrier. Lower histidine decarboxylation in the brain may alter histamine neurotransmission from the tuberomammillary nucleus to other brain regions (immunological function when released from mast cells which leads to vasodilation and permeability; however, mast cells are less numerous in the brain than other tissues (Brown et al. 2001). Altered synthesis of monoamine neurotransmitters serotonin and dopamine result from depletion of Trp and Tyr (Fig. 1.3). Adapted from (Strauss et al. 2010).

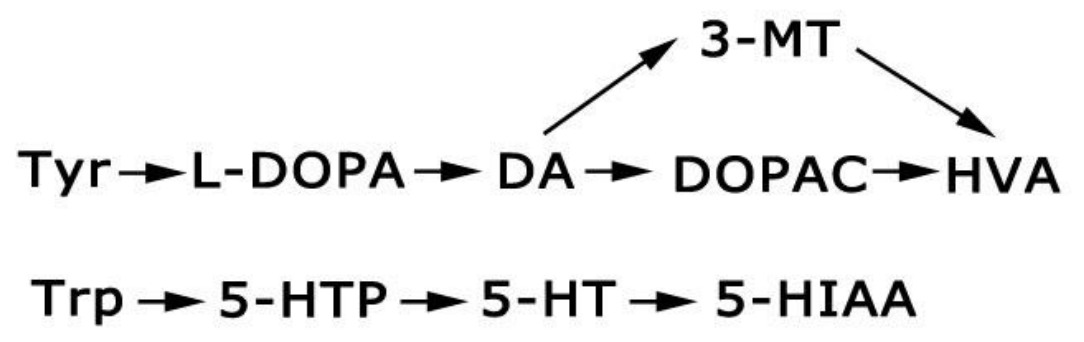

Figure 1.3. Dopamine (DA) and Serotonin (5-HT) synthesis and metabolism. Abbreviations: L-dihydroxyphenylalanine (L-DOPA); 5-hydroxytryptophan (5-HTP); 3,4dihydroxyphenylacetic acid (DOPAC); homovanillic acid (HVA, DA turnover is measured as the ratio of (DOPAC + HVA)/DA; 3- methoxytyramine (3-MT, a DA metabolite 
released into the synaptic cleft, DA release into the synaptic cleft, 3-MT/DA); 5hydroxyindoleacetic acid (5-HIAA; serotonin turnover measured as 5- HIAA/5-HT).

\subsection{Non-physiological amino acids, NPAAs}

Competition between LNAAs for transport into rat brain was documented more than 60 years ago (Christensen et al. 1948), and competition between Phe and Leu for uptake across the BBB has been confirmed in PKU patients at differing Phe levels (Knudsen et al. 1995). Pietz and coworkers (1999) were the first to demonstrate that LNAA supplementation in diet could decrease Phe levels (Pietz et al. 1999). Others (Matalon et al. 2006; Michals-Matalon et al. 2007) have successfully modified this diet with improved outcomes in PKU patients, yet the long term use of these diets may be thwarted by negative nitrogen balance (Dotremont et al. 1995; van Spronsen et al. 2010). These observations suggest that therapeutic competition for amino acid transport into the brain of individuals with aminoacidurias such as PKU may be feasible, as has been suggested by others ( McKean et al. 1968; Tews et al. 1986; Tews et al. 1990; Tews et al. 1991). Nonetheless, a systematic study of this approach has not been presented. Zinnanti and coworkers (2009) recently verified the feasibility of this therapeutic approach employing dietary supplementation with the NPAA norleucine $(\mathrm{NL})$ in mice with maple syrup urine disease (Fig. 1.2, 1.4.A). NL supplementation in this model (in which branched-chain amino acids Leu, Ile and Val accumulate) extended lifespan while improving both brain biochemistry and neurobehavioral outcomes. The work of Zinnanti extended earlier reports by Tews and Harper (1986), who showed that NL supplementation effectively lowered Phe level in rat brain. Similarly, Ennis and coworkers (1994) demonstrated that another NPAA, alpha-aminoisobutyrate (AIB; Fig. 1.4.C) could compete with Phe for transport via LAT1. LAT1 also traffics $\alpha$-methyl amino acids such as $\alpha$-methylphenylalanine, $\alpha$-methyltyrosine, and 3-O-methyldopa, which were shown to block the uptake of Phe (Uchino et al. 2002). Methylaminoisobutyric acid, MAIB (Fig. 1.4.D), is specific for the small neutral amino acid, alanine-preferring system A transporter (SAT), which is a sodiumdependent carrier that has some affinity for LNAAs such as Phe (Hargreaves and Pardridge 1988; Grewer and Grabsch 2004; Rutter et al. 2007). Finally, NB (Fig. 1.4.B) represents the prototypical NPAA inhibitor of the LAT 1-4 system (Table 1.1), yet it has never been examined systematically as a therapeutic regimen in any mammalian system or animal model. 
A<smiles>CCCCC(N)C(=O)O</smiles>

DL-norleucine (NL)
B

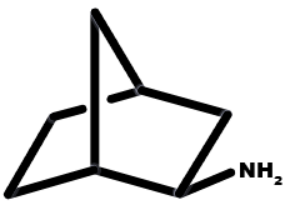

2-aminonorbornane (NB)
C

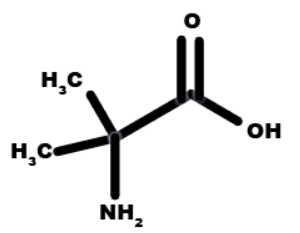

amino-isobutyric acid (AIB)
D

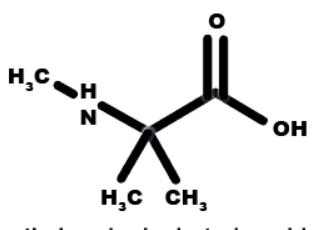

methyl-aminoisobutyric acid (mAIB)

Figure 1.4. Non-physiological amino acids (NPAA): A, norleucine (NL); $B, 2-$ aminonorbornane (NB); C, 2-aminoisobutyric acid (AIB); D, N-methyl-2-aminoisobutyric acid (MAIB). MAIB is a selective inhibitor of the A-system (see above).

\section{Amino acid transport systems at the blood-brain barrier}

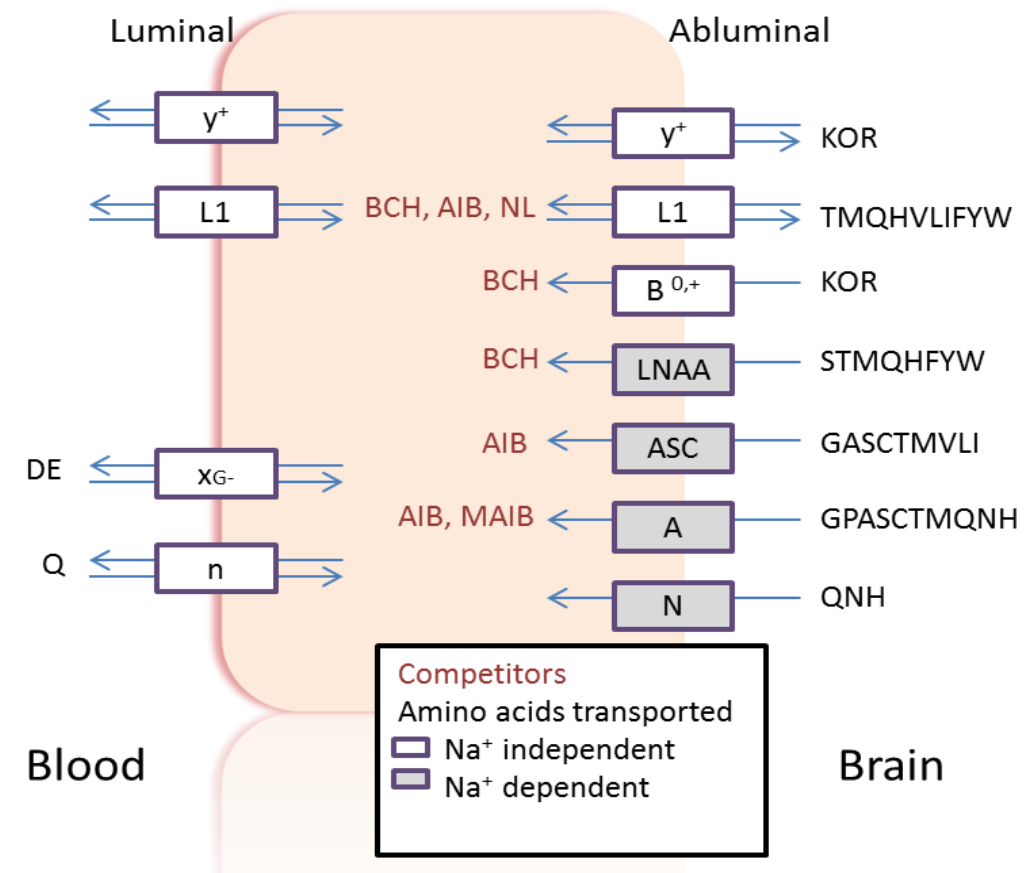

Figure 1.5. Amino acid transport systems at the blood-brain barrier (BBB). Transport system nomenclature uses one letter amino acid codes: A, alanine preferring, ASC, alanine-serine-cysteine preferring, and L1, leucine preferring. Amino acids transported are listed beside each transport system, and non-physiological amino acid competitors are shown in red (norbornane (NB) is also called 2-aminobicyclo-(2,1,1)-heptane-2carboxylic acid $(\mathrm{BCH})$ ). Gray shading signifies $\mathrm{Na}^{+}$-dependent transport, and white boxes denote facilitative amino acid exchange. 


\subsection{The $P a h^{\text {enu2 }}$ mouse}

To determine whether NPAA inhibitors of the LAT1 transporter will reduce cerebral phenylalanine, and how LAT1 inhibition might subsequently alter transport of other LNAAs, NPAAs will be administered to the $P a h^{\text {enu2 }}$ mouse. The $\mathrm{Pah}^{\text {enu2 }}$ mouse harbors a single nucleotide polymorphism converting a highly conserved phenylalanine to serine (F263S) within the enzyme catalytic domain (McDonald and Charlton 1997). Although PAH mRNA and protein are detectable in the liver, the enzyme is inactive, and homozygous animals are consistently hyperphenylalaninemic with cognitive and growth retardation (McDonald et al. 1990; UK PubMed Central 1995; Zagreda et al. 1999). Cerebral protein synthesis is decreased in this model (Smith et al. 2000), as are neurotransmitter concentrations in brain extracts (Pascucci et al. 2002; Joseph et al. 2003).

Additionally, decreased content of branched chain amino acids (Val, Ile, Leu) has been documented in the brain of hyperphenylalaninemic animal models created by administration of phenylalanine metabolism inhibitors (Puglisis-Allegra et al. 2000; Pascucci et al. 2002). The $P a h^{\text {enu2 }}$ mouse is the disease model of PKU most relevant to the human disorder and therefore most suitable for preclinical evaluation of dietary LAT inhibitors to assess efficacy. 


\section{Objective}

In this thesis project, the objective was to use non-physiological amino acids (NPAAs) to selectively restrict Phe transport into cerebral tissue. The selected amino acids used in this study (NL, NB, AIB, and MAIB) are known to, or predicted to, inhibit the different LATs. The main objective of this work is to provide preclinical data leading to translational outcomes that will provide a new treatment approach to PKU. The hypothesis is that a particular combination of NPAA inhibitors of the LAT- 1 system can be found to selectively preclude Phe from the brain. Ideally, this dosage would have minimal impact on the levels of other LNAAs in the brain. Such a treatment approach could have important clinical relevance for adolescents and adults that have difficulty adhering to a Phe-restricted diet. Blocking Phe transport could also improve suboptimal outcomes seen in some patients treated with the PKU diet alone. 


\section{Materials and methods}

\subsection{Husbandry and subject number}

To breed offspring for the experiment, polygamous breeder pairs were established with male $\mathrm{Pah}^{-/}$and female $\mathrm{Pah}^{+/}$subjects. Offspring were genotyped with tail clip extracted DNA performed at weaning (20 days of life). This was followed by PCR and restriction endonuclease digestion with BsmAl, and then visualized by agarose gel (4\%) electrophoresis, as described (Zagreda et al. 1999). Since amino acid levels are similar between $\mathrm{Pah}^{+/+}$and $\mathrm{Pah}^{+/}$ subjects, $\mathrm{Pah}^{+/-}$subjects were used as controls, obviating the need for additional husbandry to generate $\mathrm{Pah}^{+/+}$subjects. This is consistent with our laboratory's adherence to the best practices of animal usage suggested by the Association for Assessment and Accreditation of Laboratory Animal Care (AAALAC), and the objective of replacing, reducing and refining the use of animals in biomedical research. An $n=5$ sample size facilitated simple parametric statistical analysis ( $t$ test, ANOVA). This sample size was based on power calculations utilized in an unrelated study of MSUD mice in which hepatocyte transplantation was the study parameter. In that work, an $n=5$ sample size (hepatocyte-transplanted MSUD mice vs. PBS-transplanted MSUD mice) enabled us to detect a $20 \%$ reduction in the metabolic parameter alloisoleucine (pathognomonic for MSUD) with a significance of $p<0.05$. Accordingly, this number of subjects was adopted in the current study. (Protocol approval for studies with vertebrate animals IACUC L0214)

\subsection{NPAA administration}

NPAAs were administered to mice in their food to assess their potential use as interventions in PKU. Dietary compounds included $5 \%$ a-aminoisobutyric acid (AIB), 5\% DL-norleucine (NL), 0.5\% norbornane (2-aminobicyclo $(2,2,1)$ heptane2-carboxylic acid, NB), 3\% a-methyl-aminoisobutyric acid (MAIB) (Sigma Aldrich), and control chow (2018 Teklad Global Rodent Chow, 18\% protein, and extruded sterilizable 2018X). We employed 5\% (w/w) NL and AIB based upon the previous report of Zinnanti et al (2009) employing MSUD mice. The expense of NB ( $\$ 350 / \mathrm{g})$ prohibited its use at $5 \%$; accordingly, we chose $0.5 \% \mathrm{w} / \mathrm{w}(\mathrm{a}$ serendipitous choice). Two separate feeding experiments were performed. The first experiment with NL, NB and AIB used regular 18\% mouse chow from Tekklad (18R), and the second with MAIB used sterilizable, extruded $18 \%$ protein chow. Chow was made in batches of $300 \mathrm{~g}$. $18 \mathrm{R}$ was made with $300 \mathrm{~mL}$ of filtered water and mixed with drug and dehydrated 24 hours at $46^{\circ} \mathrm{C}$. $18 \mathrm{X}$ chow was made with 500 liters of autoclaved water and dehydrated 20-24 hours at $46^{\circ} \mathrm{C}$. The compounds themselves were not autoclaved. Dietary intervention was instituted at 3.5 weeks of age (post weaning and genotyping) and maintained for 3 weeks. Animals were housed under a 12 hour light/dark cycle 
with ad lib access to food and water. Mouse weights were recorded three times weekly, and food consumption calculated weekly. Blood spots were collected on Day 0 via saphenous vein puncture and capillary tube collection and spotted onto newborn screening blood spot cards (GE Healthcare) stored at $-20^{\circ} \mathrm{C}$. These were collected with the intention of looking at temporal changes in amino acid levels in blood without sacrificing the animal. At week three sacrifice, terminal blood spots, brain halves, and sera were collected into $1.5 \mathrm{~mL}$ tubes. Brain halves were flash-frozen with liquid nitrogen and stored at $-80^{\circ} \mathrm{C}$.

\subsection{High performance liquid chromatography, HPLC}

Catecholamine metabolites in $\mathrm{Pah}^{-/}$and $\mathrm{Pah}^{+/}$mouse 1/2-brain (homogenized with a 1:5 dilution of ice cold $0.1 \mathrm{M}$ perchloric acid, dithioerythritol, and diethylentriamine pentaacetic acid) were quantified by reverse-phase HPLC with electrochemical detection. Dihydroxyphenylacetic acid (DOPAC), 3methoxytyramine (3-MT), homovanillic acid (HVA), dopamine (DA), 5hydroxyindole-3-acetic acid (5-HIAA), 3-O-methyldopa (3-OMD), and serotonin $(5-\mathrm{HT})$ represent the key monoamines for our NPAA interventions (CoulArray) (Ogburn et al. 2006); HPLC and LC-MS analysis Dr. T. Bottiglieri, Baylor University Medical Center, Dallas, TX).

\subsection{Liquid chromatography tandem mass spectrometry}

LNAAs in serum and 1/2-brain were quantified using liquid chromatography-mass spectrometry (LC-MS) with electrochemical detection. Standards of $S$ adenosylmethionine (SAMe), S-adenosylhomocysteine (SAH), betaine (Bet), choline (Cho), methionine (Met), tryptophan (Trp), and tyrosine (Tyr) (Sigma). Stable isotope internal standards included betaine-d3 (BET-D3), choline-d4 (CHO-D4), methionine-d3 (MET-D3), tryptophan-d3 (TRP-D3), and tyrosine-d7 (TYR-D7) purchased from Cambridge Isotope Laboratories or CDN Isotopes INC. Stable isotope standards facilitated very accurate quantitation. Heptafluorobutyric acid and formic acid were purchased from Fluka. Ammonium acetate was purchased from Sigma, and Optima LC/MS methanol from Fisher Chemicals. The HPLC system consisted of a complete Shimadzu Prominence HPLC system with a SCL-10Avp controller. The instrument used for analysis was an ABI 4000 QTRAP LC/MS/MS system. Three groups of stock standards were prepared in $0.1 \mathrm{M} \mathrm{HCL}$ at a concentration of $1 \mathrm{mM}$ and fourth group was prepared in $0.1 \mathrm{M} \mathrm{HCL}$ at a concentration of $4 \mathrm{mM}$. All stable isotope internal standards were prepared in $0.1 \mathrm{M} \mathrm{HCL}$ at a concentration of $1 \mathrm{mmol} / \mathrm{L}$ and stored at $-80^{\circ} \mathrm{C}$. All four calibration standard groups were stored at $-80^{\circ} \mathrm{C}$ until needed. From these stock solutions a five level standard curve was prepared by diluting stock solutions in Type 1 water. Tissue samples that were previously deproteinized 1:5 with ice-cold 0.1 M PCA were thawed and spun. Samples were prepared by the addition of $150 \mu \mathrm{L}$ mobile phase A containing $20 \mu \mathrm{mol} / \mathrm{L}$ 
${ }^{2} \mathrm{H}_{3}$-SAMe to $50 \mu \mathrm{L}$ of standard or plasma and mixed by vortex. $150 \mu \mathrm{L}$ of sample mixture was added to a Microcon YM-10, $10 \mathrm{kDa}$ NMWL microcentrifugal filter unit and centrifuged for $15 \mathrm{~min}$ at $14800 \mathrm{xg}$ at $4^{\circ} \mathrm{C}$. Sample filtrate was removed and transferred to autosampler plate for analysis. $5 \mu \mathrm{l}$ were injected into the LC-MS system, described above. Solvents for HPLC were: A, 4mM ammonium acetate, $0.1 \%$ formic acid, $0.1 \%$ heptafluorobutyric acid $(\mathrm{pH}=2.5)$; $\mathrm{B}$ $100 \%$ methanol and $0.1 \%$ formic acid. All analytes were separated on a $250 \mathrm{x}$ $2.0 \mathrm{~mm}$ EZ-faast analytical column (Phenomenex) maintained at $33^{\circ} \mathrm{C}$ at a flow rate of $250 \mu \mathrm{L} / \mathrm{min}$, with a binary gradient and a total run time of $12 \mathrm{~min}$. The initial gradient condition was $75 \% \mathrm{~A}: 25 \% \mathrm{~B}$ and was ramped in a linear fashion to $100 \% \mathrm{~B}$ in $6 \mathrm{~min}$ and held constant for $1 \mathrm{~min}$. At $7.1 \mathrm{~min}$ the mobile phase was reset to initial conditions for 7 minutes. The flow from the column was delivered to the electrospray ionization (ESI) source from the period of 3 to $8 \mathrm{~min}$; otherwise the flow was diverted to waste. The compounds were detected by multiple reaction monitoring (MRM) using positive ESI with a dwell time of $30 \mathrm{~ms}$. The curtain gas was set at $15 \mathrm{~L} / \mathrm{min}$, and source gas 1 and 2 were set at 60 $\mathrm{L} / \mathrm{min}$. The heater was set to $700^{\circ} \mathrm{C}$ with an ionspray voltage of $5,000 \mathrm{~V}$ and collision gas (nitrogen) was set at $3.5 \times 10^{-5}$ Torr. All data were collected using Analyst software version 1.4.2 (Slocum et al. 1991; Puglisis-Allegra et al. 2000; Ogburn et al. 2006).

\subsection{Statistical analysis}

Metabolite data was grouped with respect to genotype $\left(\mathrm{Pah}^{+/}, \mathrm{Pah}^{-/}\right)$in order to correlate NPAA effects under normo- and hyperphenylalaninemic conditions.

Since we employed a column statistical approach (ANOVA with Tukey post-hoc), grouping by genotype significantly reduced data analysis. Analysis was performed with Graphpad Prism V5. 


\section{Results}

\subsection{Health and food consumption}

As a simple gauge of animal well-being and to verify intake of the drug, food consumption, and body weights were recorded. Food and water consumption, and body weights, did not differ significantly with respect to control cohorts as a function of treatment intervention (Table 4.1), except $5 \%$ NL. One subject died, and another was near death at sacrifice for NL. There were no outward phenotypic differences for subjects consuming NB, AIB or MAIB, as estimated from visual health inspections. Conversely, subjects consuming $5 \% \mathrm{NL}$ displayed some motor impairment, but movement anomalies were not yet quantified.

Table 4.1. Health and food consumption

Diet, genotype, average weight gain ( 3 week duration), and food consumption (Week1, 2, 3).

\begin{tabular}{|c|c|c|c|c|c|}
\hline Diet & Genotype & $\begin{array}{l}\text { Ave. } \\
\text { weight } \\
\text { gain (g) }\end{array}$ & Wk 1 & Wk 2 & Wk 3 \\
\hline \multirow[t]{2}{*}{$\begin{array}{l}18 \% \\
\text { protein }\end{array}$} & Het $(n=7)$ & 3.83 & 3.57 & 3.16 & 3.12 \\
\hline & Mut $(n=5)$ & 2.84 & 3.94 & 3.91 & 3.49 \\
\hline \multirow[t]{2}{*}{ AIB 5\% } & Het $(n=5)$ & 4.72 & 2.55 & 2.98 & 3.16 \\
\hline & Mut $(n=5)$ & 2.16 & 1.86 & 1.64 & 2.28 \\
\hline \multirow[t]{2}{*}{ NL 5\% } & Het $(n=5)$ & 1.64 & 1.95 & 2.74 & no data \\
\hline & Mut $(n=4)$ & -0.43 & 2.06 & 2.35 & $2.57^{\star}$ \\
\hline \multirow[t]{2}{*}{ NB $0.5 \%$} & Het $(n=5)$ & 5.28 & 2.99 & 3.06 & 3.05 \\
\hline & Mut $(n=5)$ & 6.38 & 2.51 & 2.89 & 2.90 \\
\hline \multirow[t]{2}{*}{$\begin{array}{l}18 X \\
\text { protein }\end{array}$} & Het $(n=5)$ & 11.96 & 2.41 & 3.69 & 3.03 \\
\hline & Mut $(n=5)$ & 4.88 & 2.04 & 3.49 & 2.44 \\
\hline \multirow[t]{2}{*}{ MAIB 3\% } & Het $(n=4)$ & 9.05 & 1.93 & 2.75 & 2.63 \\
\hline & Mut $(n=6)$ & 8.08 & 1.84 & 2.57 & 3.71 \\
\hline
\end{tabular}

\subsection{Amino acids in brain}

Amino acid levels in the brain were measured to determine the effectiveness of NPAA LAT1 competitors to reduce Phe, as well as to gauge outcomes on other LNAAs. NL, NB, and MAIB feeding significantly lowered brain Phe levels in Pah ${ }^{\text {- }}$ subjects, with NL displaying the largest reduction (even in $\mathrm{Pah}^{+/}$subjects); conversely, $5 \%$ AIB was not effective at reducing brain Phe. Although none of the dietary interventions altered Trp levels (an intriguing observation in view of 
catecholamine disturbances; see Fig. 4.3.a), pronounced effects on Tyr, BCAA and Met were seen (Fig. 4.1.a,b). Tyr levels were significantly decreased in both genotypes during NL and NB interventions, while these diets had a more pronounced effect on BCAAs in $\mathrm{Pah}^{+/}$mice (although NL did reduce BCAA levels in $P a h^{-/}$subjects). MAIB decreased Phe and Tyr levels significantly in the $\mathrm{Pah}^{-/}$ subjects ( $p<0.005$ and $p<0.05$ respectively), and did not significantly alter total BCAA (sum of Val, Leu, and Ile). NL, NB, and AIB decreased Met levels in $\mathrm{Pah}^{+/-}$ subjects, and both NB and AIB feeding resulted in decreased Met levels in Pah ${ }^{-/}$ subjects. MAIB did not alter Met levels (Fig. 4.1.b). NL intervention significantly reduced SAMe, in both genotypes. We extended SAMe studies by measuring the associated sulfhydryl analogue, S-adenosylhomocysteine (SAH; see bottom right quadrant, Fig. 4.2.), in which the effects of NL on SAMe were reproduced with respect to $\mathrm{SAH}$. As for SAMe, SAH levels were not different by genotype in control cohorts (no NPAA). Moreover, we found a hypercorrection of SAH levels with NB feeding (Fig. 4.2.a; $p<0.05$ with respect to control). Although no significant difference in SAMe was observed with MAIB, brain SAH levels were decreased $(p<0.001)$.

We next performed $t$-test analyses of each NPAA diet as a function of genotype (not shown in Fig. 4.1.a). These analyses revealed significant differences between $\mathrm{Pah}^{+-}$and $\mathrm{Pah}^{-/}$subjects as follows: Phe (control and all diets, as expected); Tyr, only AIB and NB; Trp and BCAAs, only in control; Met, control and AIB; SAMe and SAH (Fig. 4.2.a,b), only AIB, and SAH only for MAIB. Of interest (Fig. 4.1.a) was the observation of a lack of a significant difference for Tyr with respect to genotype (in the absence of dietary intervention), perhaps explaining why dopamine anomalies are less pronounced than serotonin defects in $\mathrm{Pah}^{-/}$subjects 

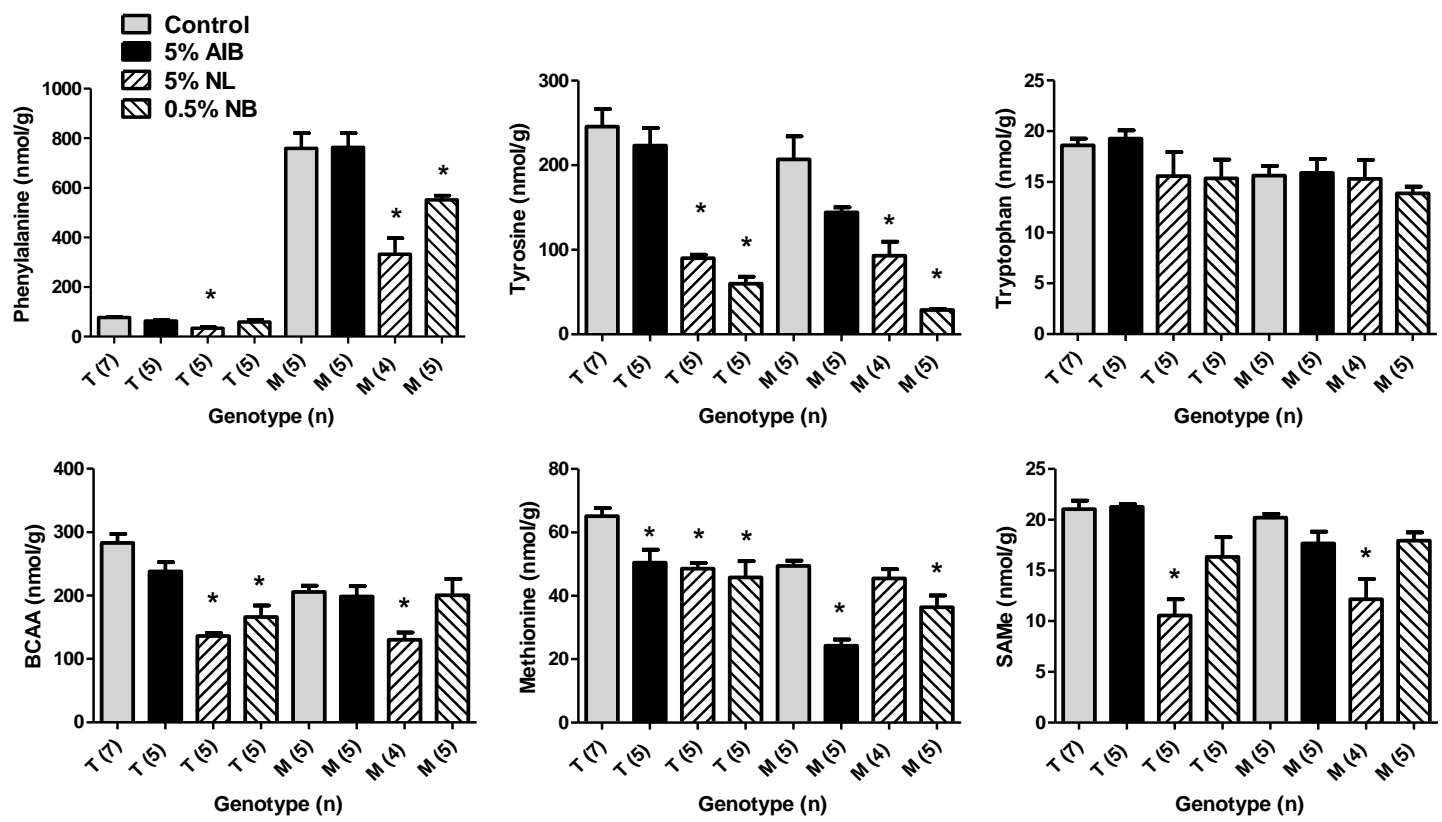

Figure 4.1.a. Brain LNAAs and SAMe as a function of diet (NL, NB, AIB) and genotype $\left(\mathrm{T}, \mathrm{Pah}^{+/} ; \mathrm{M}, \mathrm{Pah}^{-/}\right)$. Brain LNAA levels, and that of the methionine derivative $S$ adenosylmethionine (SAMe), are shown in Fig. 4.1. SAMe measurements were proposed to assess possible downstream effects if alterations of Met levels were encountered during NPAA consumption (see below). Moreover, for ease of presentation, values were summed for Ile, Val and Leu (branched-chain amino acids (BCAAs)). Statistical analysis (one way ANOVA with Tukey post-hoc) compared cohorts with and without NPAAs, and within genotype only ( ${ }^{*} p<0.05$ compared to control). 

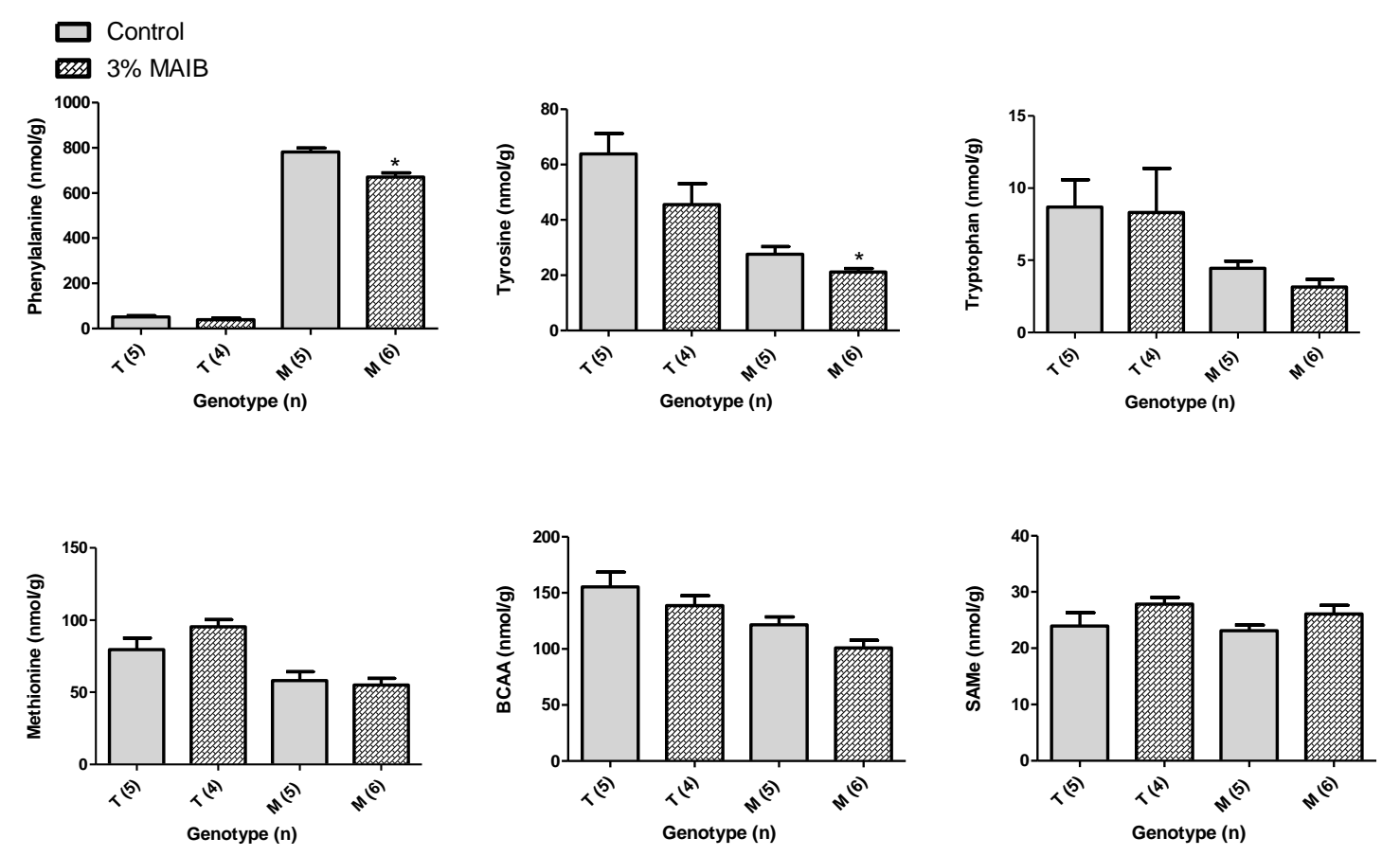

Figure 4.1.b. Brain LNAA and SAMe as a function of diet (MAIB) and genotype (T, $\left.\mathrm{Pah}^{+/} ; \mathrm{M}, \mathrm{Pah}^{-/}\right)$. Evaluation of dietary intervention with $3 \%$ MAIB in Pah ${ }^{\text {enu2 }}$ mice. Statistical analysis (unpaired two-tail $t$-test) compared cohorts with and without MAIB, and within genotype only ( ${ }^{*} p<0.05$ compared to control).

\subsection{Amino acids in sera}

Quantification of amino acids in sera provides an indication of possible LAT competition and nutrient absorption in the gut. Analyses of amino acids in sera demonstrated fewer significant differences and more variability than those in brain (Fig. 4.2) (potentially associated with smaller subject numbers for NL). Further, small sera volumes did not enable us to measure SAMe and SAH. AIB intervention had a significant impact on blood Met (consistent with brain results) and $\operatorname{Trp}$ (Fig. 4.2.a). None of the dietary interventions significantly altered blood Phe, perhaps suggesting a lack of effect on Phe uptake in the gut. We again performed $t$-test analyses for each intervention as a function of genotype, and observed significant differences between $\mathrm{Pah}^{+/-}$and $\mathrm{Pah}^{-/}$subjects as follows: Phe (control and all diets, as expected); Tyr, both control and NB feeding; BCAAs, control only. There were no significant differences observed for Trp and Met. The trend for sera BCAA was toward higher levels in $\mathrm{Pah}^{-/}$subjects, which could potentially reflect catabolism associated with muscle proteolysis and BCAA release. 

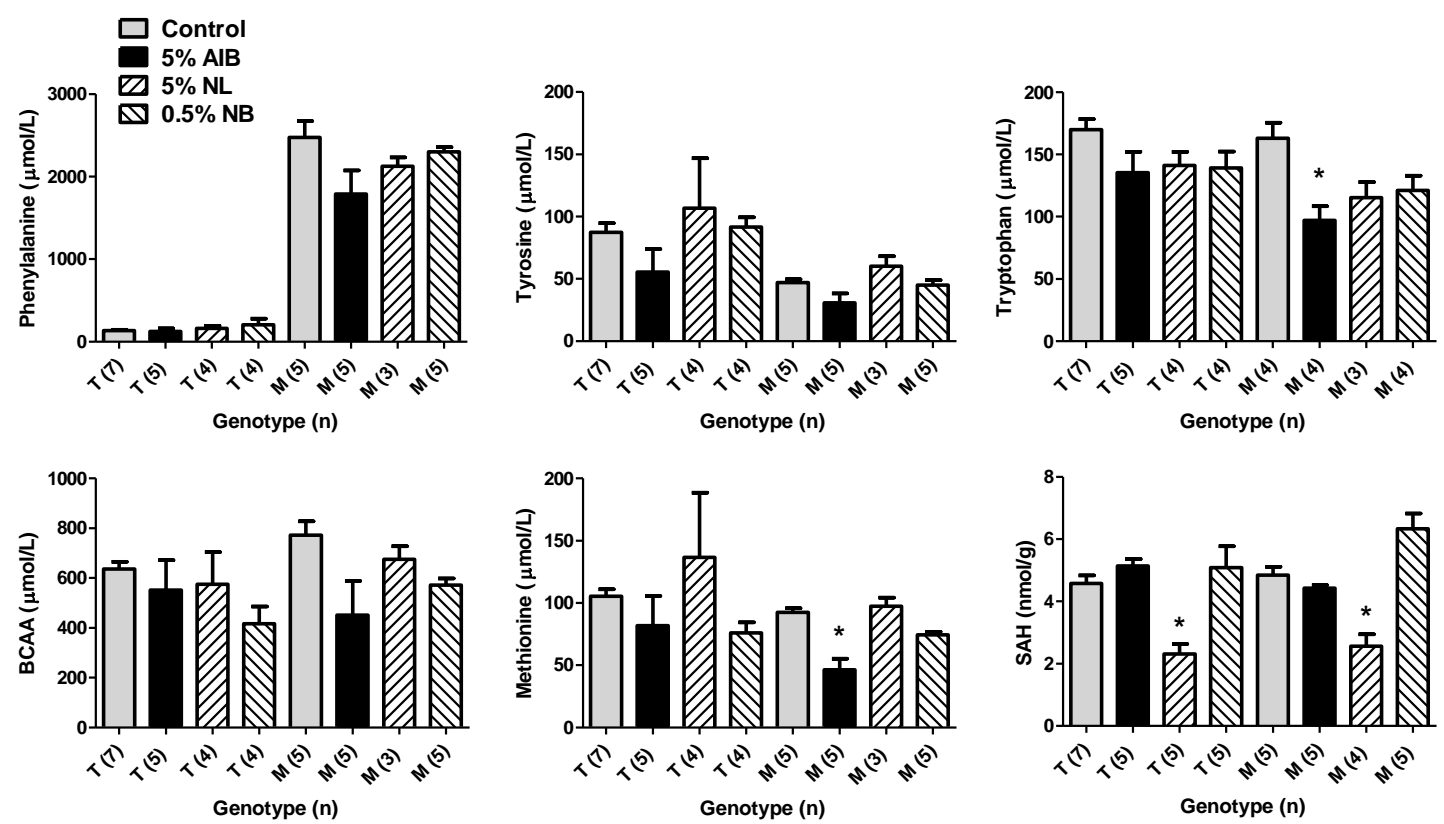

Figure 4.2.a Sera LNAAs and SAH as a function of diet (NL, NB, AIB) and genotype (T, $\left.\mathrm{Pah}^{+/} ; \mathrm{M}, \mathrm{Pah}^{-/}\right)$. See Fig. 4.1.a legend for abbreviations and statistical analysis. Note: brain SAH shown in the bottom right quadrant (pertinent to Fig. 4.1.a).
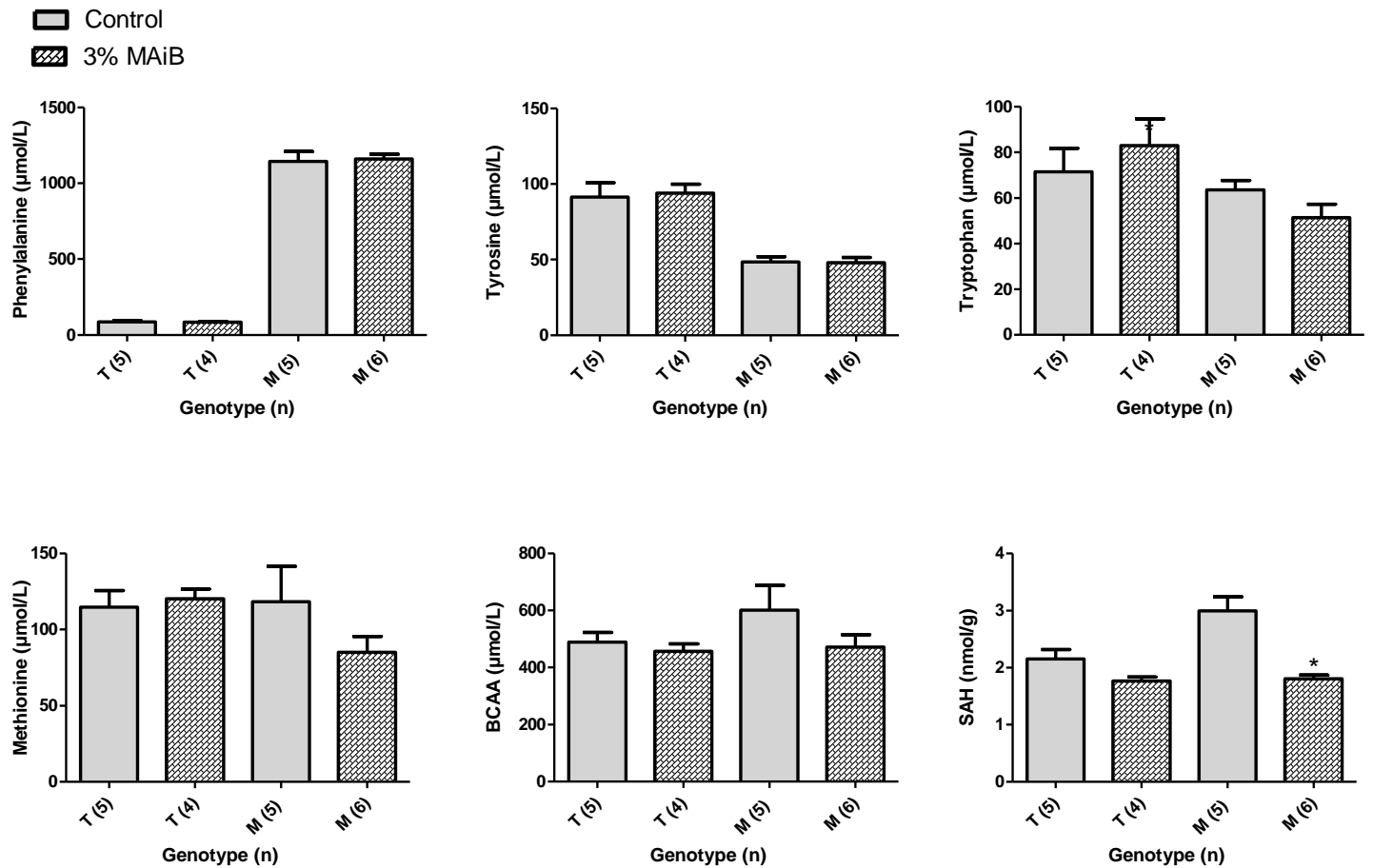

Figure 4.2.b. Sera LNAAs and SAH as a function of diet (MAIB) and genotype (T, $\mathrm{Pah}^{+/}$; M, Pah $\left.{ }^{-/}\right)$. See Fig. 4.1.b legend for abbreviations and statistical analysis. Note: 
brain SAH shown in the bottom right quadrant (pertinent to Fig. 4.1.b). No significant alteration of serum LNAAs occurred with MAIB feeding.

\subsection{Catecholamine levels in brain}

Determining deficiency or restoration of serotonin, 5-HT and/or dopamine, DA, precursors and turnover in the brain signifies important effects of NPAA administration on locomotor and social function in the mice. Catecholamine analyses with respect to dietary intervention are shown in Fig. 4.3.a,b. There were no differences for DOPAC, HVA and DA release (quantified as the 3MT/DA ratio with respect to AIB, NL, or NB for either genotype. For MAIB, these, as well as 3-MT, were decreased in the brain for both genotypes. MAIB feeding reduced metabolites in the DA and 5-HT systems. In the Pah ${ }^{-1}$ mouse, the turnover of DA and 5-HT were reduced, and in the $\mathrm{Pah}^{+/}$mouse DA and 5-HT themselves were reduced. AIB feeding did not alter any metabolite with respect to control cohorts (Fig. 4.3.a). NL feeding did not significantly alter the DA system, but did impact 5-HT and 5-HIAA levels in Pah ${ }^{+/}$subjects. NB feeding markedly affected both DA and 5-HT systems (Fig. 4.3.a), with significant decreases of DA in both genotypes, and 3-MT in Pah ${ }^{-/}$subjects. As well, NB significantly decreased 5-HT in $\mathrm{Pah}^{+/}$and $\mathrm{Pah}^{-/}$subjects. NB feeding did not alter 5-HIAA levels in either genotype, while the turnover of both DA and 5-HT was markedly increased in both $\mathrm{Pah}^{+/-}$and $\mathrm{Pah}^{-/}$subjects. Again, $t$-test analyses for each dietary intervention as a function of genotype were carried out, which revealed significant differences between $\mathrm{Pah}^{+/}$and $\mathrm{Pah}^{-/}$subjects as follows:

DA, control and all diets except NL (this was also the case for 5-HT turnover); 3MT, all diets but not the control cohort; 5-HT and 5-HIAA, all groups and interventions; and DA turnover, only for NL and NB. Overall, these findings agree with previous analyses of PKU mice, with the exception of a lack of significant difference in the control cohort for DA turnover. 

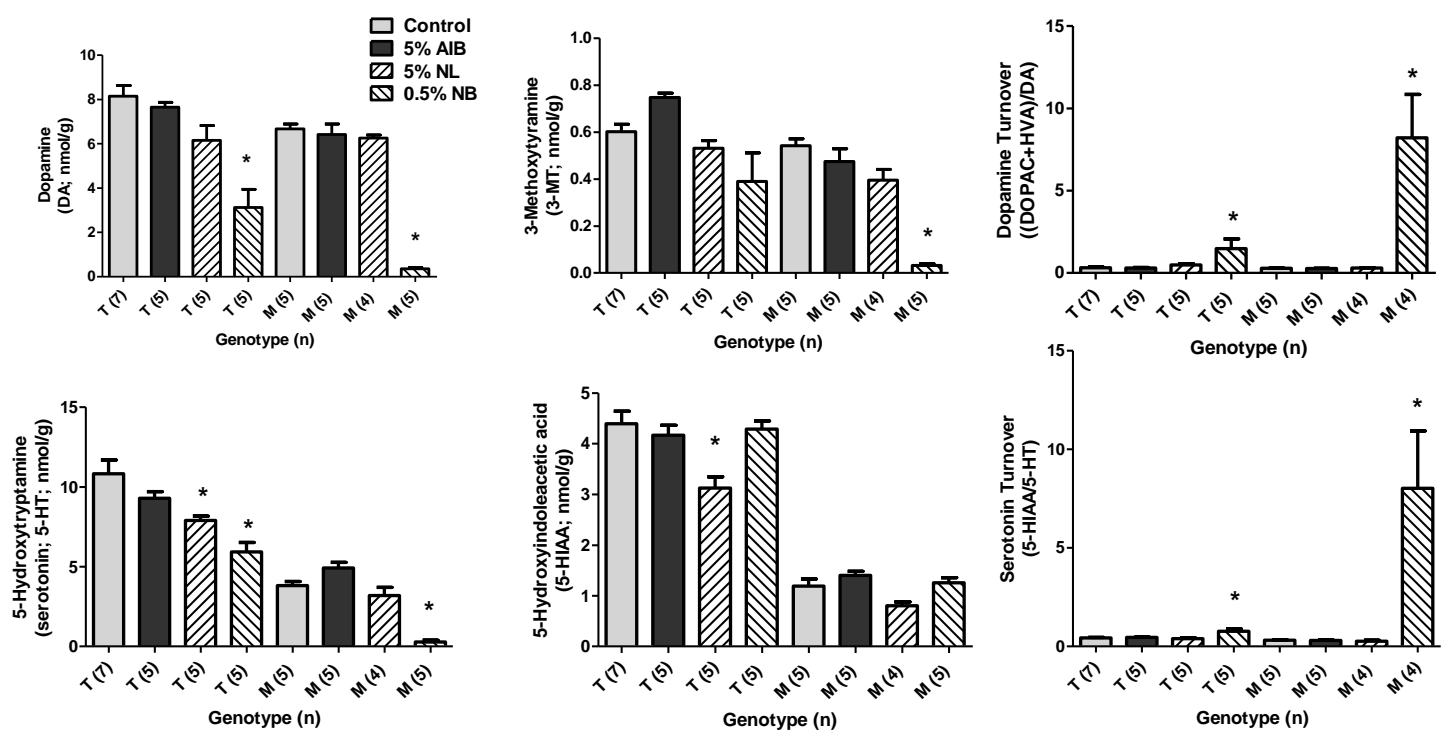

Figure 4.3.a. Brain catecholamines as a function of diet (NL, NB, AIB) and genotype $\left(\mathrm{T}, \mathrm{Pah}^{+/} ; \mathrm{M}, \mathrm{Pah} h^{-/}\right)$. See Fig. 4.1.a for abbreviations. Statistical analysis performed as for Figs. 4.1.a \& 4.2.a $\left(^{*} p<0.05\right)$. 

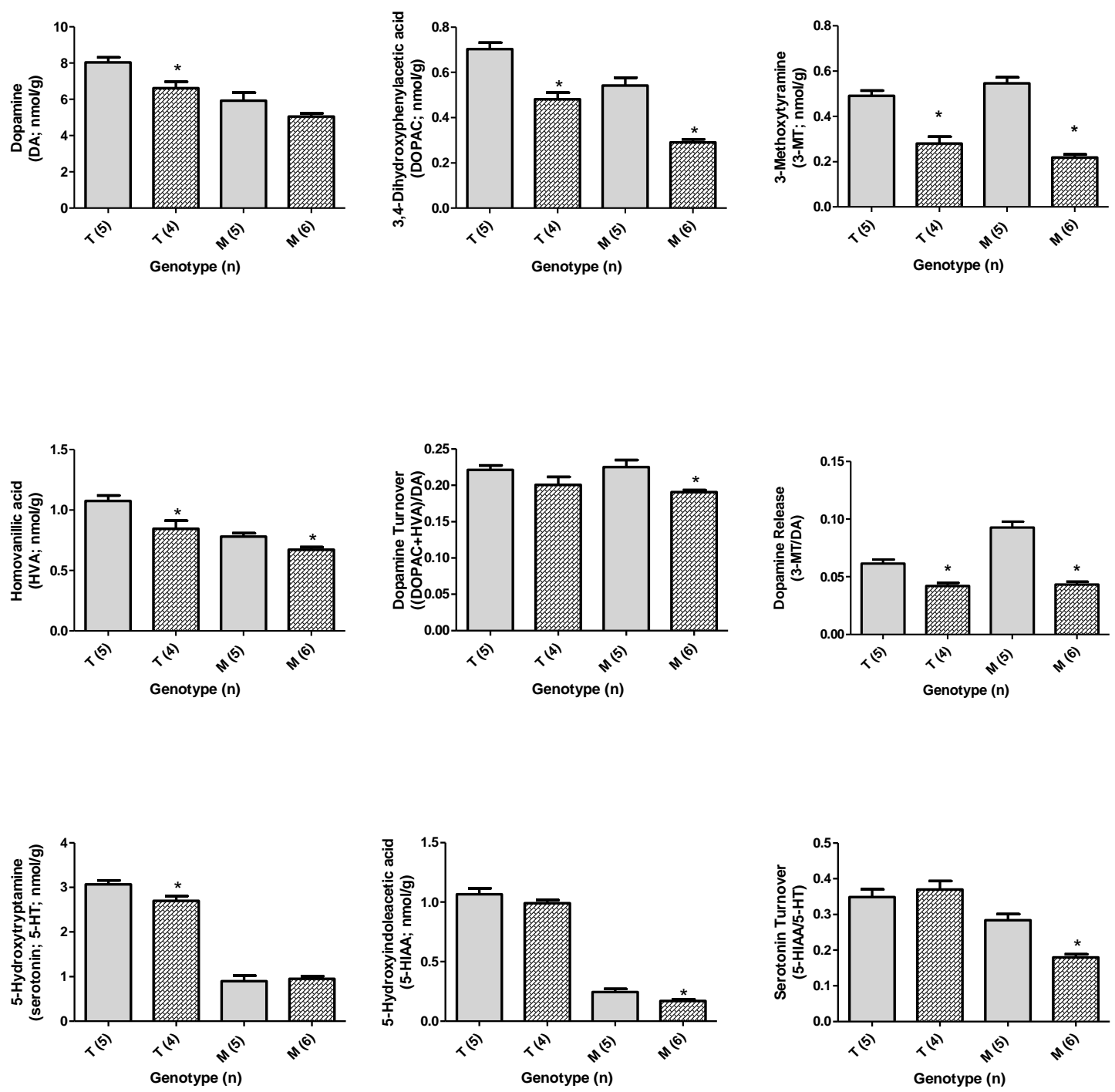

Figure 4.3.b. Brain catecholamines as a function of diet (MAIB) and genotype (T, $\left.\mathrm{Pah}^{+/} ; \mathrm{M}, \mathrm{Pah}^{-/}\right)$. Statistical analysis performed as for Figs. 4.1.b \& 4.2.b $\left({ }^{*} \mathrm{p}<0.05\right)$.

\subsection{NPAA levels in brain and blood}

NPAA consumption does not guarantee absorption or transport. Ideally, systemic and repetitive measurement would provide the best measure of the pharmacokinetics and dose-response to validate the Phe-reducing capacity of our interventions. To this end, both NL and NB have been quantified in terminal samples of sera and brain using an HPLC-based methodology. In five subjects, 
the sera NL concentration was $3.11 \pm 0.41 \mathrm{mM}$ (SD; range 2.57-4.75) while that in brain was $822 \pm 27 \mathrm{nmol} / \mathrm{g}$ tissue (assuming a tissue density approximating water, $\sim 0.82 \mu \mathrm{M})$. For $\mathrm{NB}$, the sera concentration was $0.21 \pm 0.11 \mathrm{mM}(\mathrm{SD}$; range $0.08-0.31, n=4)$, while that in brain was $276 \pm 104 \mathrm{nmol} / \mathrm{g}$ tissue $(\mathrm{n}=9)$, or $\sim 0.28 \mu \mathrm{M}$. These values indicate both absorption and uptake into brain, and roughly reflect the 10 -fold difference in level of application ( $5 \% \mathrm{NL}, 0.5 \% \mathrm{NB}$ ). An HPLC and tandem mass spectrometry-based method to quantify both AIB and MAIB in tissue extracts and blood is in progress.

\subsection{Effect of NL feeding on blood chemistries}

Subjects $\left(\mathrm{Pah}^{+-}\right)$were supplemented with $5 \% \mathrm{NL}(\mathrm{n}=7)$ or standard chow $(\mathrm{n}=6)$ for 3 weeks, after which sera was isolated for blood chemistries. The latter included glucose, blood urea nitrogen (BUN), creatinine, total protein, albumin, phosphorus, $\mathrm{Na}^{+}, \mathrm{Cl}^{-}, \mathrm{K}^{+}$, total $\mathrm{CO}_{2}$, cholesterol, triglycerides, $\mathrm{Ca}^{++}$, total bilirubin, alkaline phosphatase (ALP), alanine aminotransferase, and gamma-

glutamyltransferase. No significant differences were observed between cohorts, with two exceptions: BUN $(5.43 \pm 0.30 \mathrm{mg} / \mathrm{dL}(+\mathrm{NL})$ vs. $3.83 \pm 0.17$ (no NL) $(p=0.001$; two-tailed $t$-test); and ALP $(41.6 \pm 4.0 \mathrm{U} / \mathrm{L}(+\mathrm{NL})$ vs. $57.7 \pm 2.3$ (no NL) $(p=0.0065)$. It is unclear why NL supplementation would depress ALP, since other hepatic enzymes were normal. On the other hand, it appears that NL is contributing to an increased BUN via transamination, and thus careful monitoring of blood chemistries will be prudent for future studies. This observation suggests that NL is at least somewhat metabolizable in the body, perhaps in the liver, but also potentially by intestinal bacteria (Der Garabedian and Vermeersch 1987).

\section{Discussion}

These interventional studies represent the first application of $\mathrm{NL}$ and $\mathrm{AIB}$ in an model of PKU, and the first in vivo application of NB in any mammal. MAIB has been used to study transport of amino acids across the blood-nerve barrier in rats, where MAIB was found to have no inhibitory effect on blood to nerve influx of Phe using intravenous injection (Wadhwani et al. 1990). The Phe-reducing capacity of both NL, NB (Fig. 4.1.a) and MAIB (Fig. 4.1.b) provides proof-ofprinciple to support further characterization of these compounds. Unfortunately, neither species selectively acted on Phe (at the concentrations employed), with significant effects on other LNAAs and catecholamines. NL did, however, normalize DA levels and 5-HT turnover between genotypes, pointing to a positive effect on catecholamines. Despite its inability to lower Phe, AIB warrants further evaluation at higher concentrations, especially since its effects on other biomarkers (LNAAs, catecholamines, etc.) were much milder than those of NL and NB. 
A novel finding in these studies was the effect of MAIB on LNAA transport. MAIB is purported to be a specific A-system inhibitor (Fig. 1.5), yet it significantly reduced Phe and other LNAAs, and had a pronounced effect on the dopamine system in both genotypes. Overall the data suggests that MAIB may be the target compound with the most potential to reduce Phe with the least effect on other LNAAs in the brain. Indeed, feeding of 3\% MAIB had no effect on Met and Trp, and the mildest effect on Tyr of any of the treatments attempted (-1:30, $56: 55,27: 86,14: 25$, percent decrease Phe:Tyr for $5 \%$ AIB, $5 \%$ NL, 0.5\% NB, and $3 \%$ MAIB respectively as compared with control diet (Table 5.1). Data is currently being collected to confirm that MAIB altered small amino acid levels in the brain, such as alanine and proline.

Table 5.1.

NPAA effects on Phe and Tyr in $\mathrm{Pah}^{-/}$subjects. *mean value in $\mathrm{nmol} / \mathrm{g}$

\begin{tabular}{|c|c|c|c|c|c|c|}
\hline \multicolumn{7}{|c|}{ Phenylalanine } \\
\hline & $(-)$ & & & & $(-)$ & \\
\hline Diet & $18 \%$ & $5 \%$ AIB & $5 \% \mathrm{NL}$ & $0.5 \% \mathrm{NB}$ & $18 \% X$ & $3 \%$ MAIB \\
\hline means* & 759 & 764 & 333 & 552 & 782 & 671 \\
\hline$p$-value & & $p=0.96$ & $\mathrm{p}=0.002$ & $\mathrm{p}=0.026$ & & $p=0.002$ \\
\hline percent & & -1 & 56 & 27 & & 14 \\
\hline
\end{tabular}

\begin{tabular}{|c|c|c|c|c|c|c|}
\hline \multicolumn{7}{|c|}{ Tyrosine } \\
\hline Diet & $\begin{array}{l}(-) \\
18 \% \\
\end{array}$ & $5 \%$ AIB & $5 \% \mathrm{NL}$ & $0.5 \% \mathrm{NB}$ & $\begin{array}{l}(-) \\
18 \% \mathrm{X}\end{array}$ & $3 \%$ MAIB \\
\hline means ${ }^{*}$ & 207 & 144 & 93 & 29 & 28 & 21 \\
\hline$p$-value & & $p=0.056$ & $p=0.01$ & $p=0.0002$ & & $\mathrm{p}=0.049$ \\
\hline percent $\downarrow$ & & 30 & 55 & 86 & & 25 \\
\hline
\end{tabular}

As revealed in these studies, a major challenge will be to minimize LNAA effects (other than Phe) with our interventions. Monoamine and LNAA data indicate that $5 \%$ and $0.5 \%$ NL and NB, respectively, are too high and $5 \%$ AIB is insufficient for optimal intervention. Tyr levels were clearly impacted, and to a lesser extent Met and BCAA levels (Fig. 4.1.a). Moreover, despite an absence of altered Trp levels, we observed significant alterations of the serotonin system along with dopamine disturbances (Fig. 4.3.a). Mounting evidence indicates that dopaminergic and serotoninergic disruptions in PKU patients contribute significantly to long-term pathophysiology (Waisbren et al. 2010; de Groot et al. 2010; Brumm et al. 2010; Banerjee et al. 2011). Biosafety information for our NPAAs will have utility in terms of preclinical studies. Anecdotal evidence suggests that NL, AIB, NB and MAIB are not extensively metabolized in mammals, yet systematic metabolic analyses for any of these compounds is lacking, and will also be investigated in further studies. As well, NPAAs not 
degraded by mammalian cells may still be metabolized by intestinal bacteria. For example, NL is transaminated in the gut by Candida, and it may be a substrate for amino acid oxidase (Der Garabedian and Vermeersch 1987). Indeed, serological data indicates that feeding $5 \% \mathrm{NL}$ to $\mathrm{Pah}^{+/}$subjects elevated blood urea nitrogen. AIB (also called 2-methylalanine) is metabolized by at least one bacteria (Aaslestad et al. 1964). No data is available on the metabolism of MAIB or NB in mammals.

The approach employing NPAAs should be applicable to another disorder of LNAA metabolism, MSUD (maple syrup urine disease), a screenable disorder in which the primary amino acids that accumulate to supraphysiological levels are leucine, isoleucine and valine. Knudsen and colleagues (1995) documented competition between Phe and Leu for uptake across the BBB in PKU patients, and the $K_{m}$ values for Phe $(32 \pm 9 \mu \mathrm{M})$ and Leu $(87 \pm 11 \mu \mathrm{M})$ uptake into rat brain are comparable (Pardridge et al. 1975), all of which leads to the conclusion that NPAA intervention should be efficacious in MSUD (Zinnanti et al. 2009).

Similarities in pathomechanisms do not imply comparable pathophysiology, however, and preclinical studies comparable to those outlined above would be required in the corresponding MSUD animal model (Skvorak et al 2009a; 2009b; Strauss et al. 2010). 


\section{Future directions}

In these studies, the variable of nitrogen load in the control cohort was not fully addressed; however, in future studies, casein in control (no NPAA) cohorts will be used to attempt to control for nitrogen load with NPAA administration. Casein, a milk protein utilized by Harlan-Teklad in the preparation of their rodent diets (www.harlan.com), will be used to attempt to maintain isocaloric and nitrogenbalanced diets for control cohorts. Additionally, optimal NPAA interventions will be examined in combination with regular (Teklad T.2018M; 18\% protein) and low protein (Teklad TD.90016; 6\% protein) diets that will recapitulate the clinical setting of PKU patients. Similarly, examination of NPAAs in Phe-limited chow would most closely mimic the clinical situation for long-term studies.

The long-range goal of these studies is to find a combination of NPAA interventions that can selectively block gut absorption and brain transport of Phe with minimal impact on other LNAAs. While optimistic about this goal, an additional approach is to consider supplementation of downstream LNAA analogues in my studies in the Pah ${ }^{\text {enu2 }}$ mouse. Three compounds, SAMe, nitisinone, and 5-HTP (Table 6.1; Fig. 6.1), are proposed to potentially circumvent the problems associated with non-Phe inhibition of LAT. Optimally, the intermediates should employ non-LAT systems for brain access, since the latter is our therapeutic target. This is the case for SAMe and nitisinone, but remains in question for 5-HTP. Some evidence suggests that 5-HTP (the serotonin precursor) accesses the brain via the serotonin (5-HT) transporter, but there is no consensus and it may be partially moved on the LAT (Nakatani et al. 2008). The rationale for the application of nitisinone in these studies centers on blocking systemic Tyr degradation (the clinical efficacy of this drug applicable to tyrosinemia type I) with concomitant elevation of circulating Tyr (McKiernan 2006). The latter should lead to increased brain Tyr, but there may be competition with the NPAAs. Nonetheless, additional competition from 5-HTP and Tyr (associated with nitisinone administration) with different LATs would be desirable and may further curtail brain Phe levels. Since it utilizes the nucleoside transporter, SAMe intervention avoids concerns with LAT competition (Chishty et al. 2002), and is rational based upon preliminary findings with NL (Fig. 4.1.a). 
Table 6.1.

NPAA interventions proposed to counteract NPAA-related decreases of non-Phe LNAAs. *(NTBC,2 -[2-nitro-4-(trifluoromethyl)benzoyl] cyclohexane-1,3-dione), an inhibitor of Tyr degradation.

\begin{tabular}{|c|c|c|c|}
\hline Compound & Transporter & Rationale & Citations \\
\hline 5-HTP & $5-\mathrm{HT}$ & $\begin{array}{l}\text { Bypass LAT, maintain } 5-\mathrm{HT} \\
\text { level }\end{array}$ & $\begin{array}{l}\text { (Andolina et al. } \\
\text { 2011) }\end{array}$ \\
\hline $\begin{array}{l}\text { NTBC* } \\
\text { Nitisinone }\end{array}$ & - & $\begin{array}{l}\text { Increase systemic Tyr, } \\
\text { raise DA level }\end{array}$ & (McKiernan 2006) \\
\hline SAMe & Nucleoside & $\begin{array}{l}\text { Bypass LAT, offset Met } \\
\text { depletion }\end{array}$ & $\begin{array}{l}\text { (Chishty et al. } \\
\text { 2002) }\end{array}$ \\
\hline A & (TP) & C & (SAMe) \\
\hline
\end{tabular}

Figure 6.1. Supplements proposed to bypass LAT. Chemical structures of interventions employed to supplement non-Phe LNAA decreases during NPAA intervention.

An additional strategy is supplementation of threonine (Thr). Segawa and colleagues (1999) provided evidence for a $\mathrm{Na}^{+}$-independent intestinal transport system for Phe and Thr, and Sanjurjo and coworkers (2003) built upon this observation by demonstrating a significant reduction of blood Phe in PKU patients receiving Thr supplementation, presumably the result of decreased intestinal absorption of Phe due to competition (Sanjurjo et al. 2003). Thr supplementation has not been piloted in $\mathrm{Pah}^{-/}$mice, and its use in combination with our NPAAs may provide a more even mix of essential amino acids in the murine system, but the risk with Thr feeding is that the patient, or mouse, is driven into negative nitrogen balance. Conversely, glycomacropeptide (GMP; substantially Phe-free) has been successfully piloted in $\mathrm{Pah}^{-/}$mice (Ney et al. 2008; Laclair et al. 2009). GMP administration significantly increases blood Thr, while simultaneously generating an inverse correlation between Thr and Phe in brain (decreased Phe with increasing Thr). Accordingly, GMP may represent another mechanism for increasing $\mathrm{Thr}$ in $\mathrm{Pah}^{-/}$mice and further inhibiting Phe transport into brain. In the long run, however, the goal is to utilize only one (or 
more) of the NPAAs piloted in this thesis work to selectively lower Phe content in brain. The use of additional interventions (SAMe, nitisinone and 5-HTP) would be a complicated approach in a patient, might not be significantly more welcome by patients than the protein-restricted diet, and actually might have more potentially negative downstream metabolic effects than just the NPAAs alone.

Catecholamines in these studies employed $1 / 2$-brains (sagitally sectioned), which may not be optimal. For example, it is possible that the DA level determined in $1 / 2$-brain extract was misleading (Fig. 4.3.a), such that low levels of DA in striatum may have been "normalized" via mixing of higher DA levels in cortex or cerebellum (or other brain regions) (Bortolozzi et al. 2003). With this rationale in mind, dissected brain regions, including cortex, striatum, cerebellum and hippocampi will be monitored during catecholamine measurements in future work. Additionally, neurobehavioral assessments will be made to complement terminal catecholamine quantifications once more optimal NPAA interventions and combinations are assessed. The rationale for behavioral assessment focuses primarily on the neurocognitive deficits observed in PKU patients (Banerjee et al. 2011), as well as the roles of DA and 5-HT in cognition and movement (Uddén et al. 2010). Locomotor, anxiety, and non-spatial memory are relevant endpoints for $\mathrm{Pah}^{-/}$subjects. For initial motor evaluation, subjects are characterized using a quantitative neurological scale (0, normal animal; 10 , animal displaying near-death recumbency) that examines dystonic movement and behavior (Ouary et al. 2000; Zinnanti et al 2009; Zinnanti et al. 2012). Visual-cliff avoidance response (CAR) gauges teratological learning impairment in mice (Yoshida et al. 2000). Additionally, open field (OF) activity will be used to obtain a broader behavioral coverage of serotoninergic function (Singer et al. 2009). The OF test assesses exploratory and anxiety-like behavior, a useful measure of behavioral response to novelty (see Fig. 6.2). The Gibson laboratory OF area consists of an enclosed white circular arena, with division markings and floor holes. Animals experiencing higher anxiety will remain in the outermost circle of the arena, avoiding the center (thigmotaxis). In addition, the number of head dips and the novel object test evaluates the animal's exploration of the field. Locomotor activity parameters measured include: quadrant transitions and velocity, as well as the number of quadrants explored. These evaluations should represent valid surrogates for behavior associated with DA and 5-HT function, and can be assessed during intervention without the need to sacrifice the animal. 


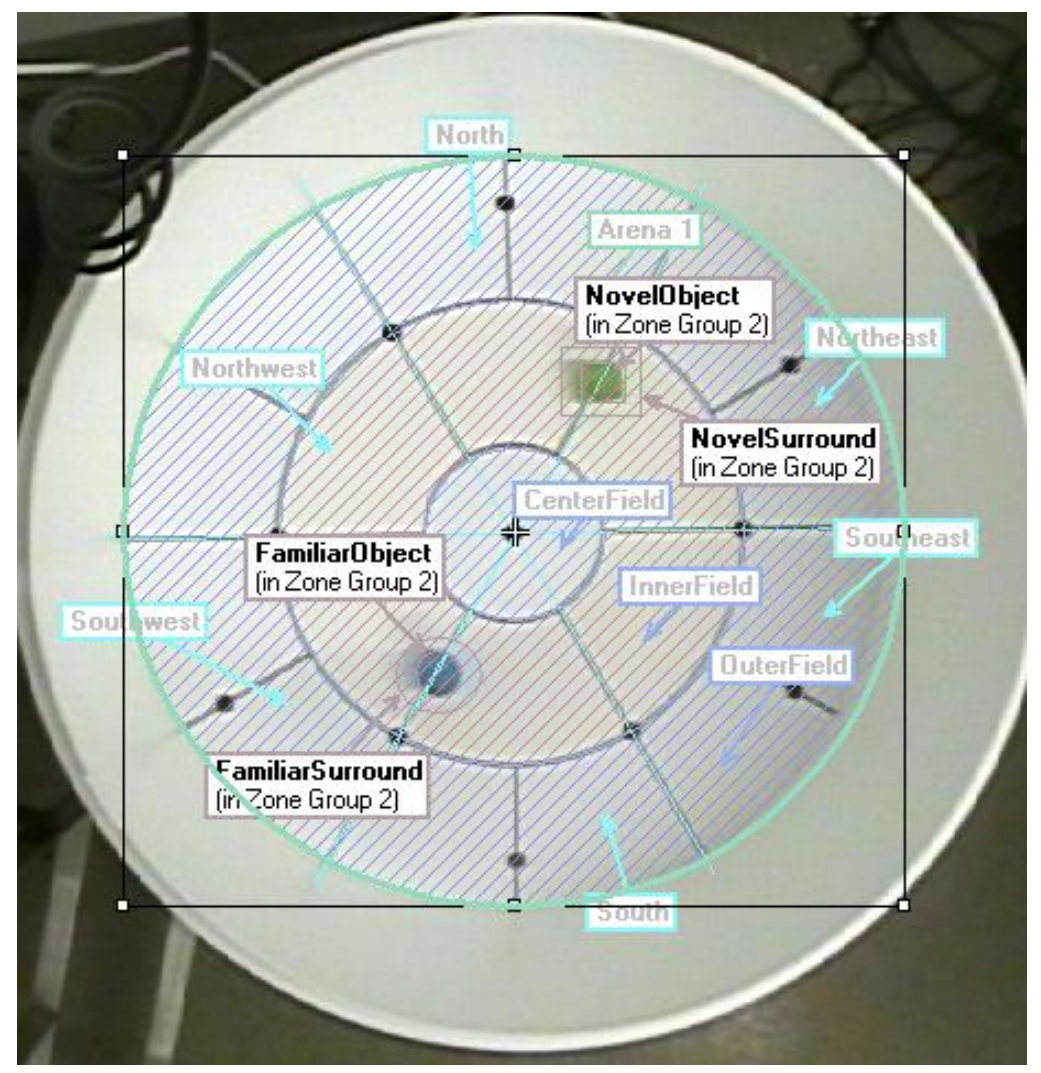

Figure 6.2. Open field testing paradigm for behavioral testing in mice. Three zone groups are established to determine anxiety, non-spatial memory, and locomotor activity.

Finally, since a primary goal of PKU intervention is to examine therapeutic strategies that improve cognitive dysfunction, the memory of $P a h^{\text {enu2 }}$ mice receiving NPAA administration must be explored. The object recognition (OR) test evaluates non-spatial working memory and is based on the premise that mice are instinctively curious. Outputs measures here include the amount of time spent in the zone of the familiar versus novel object. First the activity in the arena is recorded in the settings with two familiar objects. After a rest outside the field, the animal is replaced into the same quadrant and left to explore the novel object, with the assumption that animals with higher working memory will investigate the novel object preferentially (Bevins et al. 2006). Noldus Ethovision software and video recording will be used to track animals in the field, providing the outputs described for the OF and novelty testing for the mice. An example of the zoning and quadrature of the field is depicted in Fig. 6.2. Overall, these behavioral tests will gauge anxiety, memory, exploratory and locomotor activity providing important behavioral readouts for the effectiveness of interventions used to treat $P a h^{\text {enu2 }}$ mice. 


\section{Conclusion}

NL, NB and MAIB have significantly reduced Phe levels in the phenylketonuric mouse brain, but with concomitant alterations of important biomolecules for serotoninergic and dopaminergic neurotransmission, and other LNAAs.

Nonetheless, the pilot data shown in this thesis indicates that this novel approach is feasible and may be the genesis of a totally new treatment for PKU patients. Moreover, for the first time here it is shown that a system A specific inhibitor, MAIB, may have important utility as a LAT-1 inhibitor, and this has not been reported in the literature. Utilizing NPAAs to reduce cerebral Phe transport is pertinent to the long-term objective of employing oral NPAA intervention(s) in patients for whom dietary adherence to low-protein intake is suboptimal, and potentially to identify NPAA interventions that would enable normal dietary protein intake for patients. What remains as a barrier is to optimize concentration, possibly in combinatorial dosages of NPAA, to produce a cocktail with selective Phe-inhibiting capacity. 


\section{Bibliography}

Aaslestad, H G, and A D LARSON. 1964. "Bacterial Metabolism of 2Methylalanine." Journal of Bacteriology 88 (November): 1296-1303.

Anastasoaie, Vera, Laura Kurzius, Peter Forbes, and Susan Waisbren. 2008. "Stability of Blood Phenylalanine Levels and IQ in Children with Phenylketonuria." Molecular Genetics and Metabolism 95 (1-2) (October): 17-20. doi:10.1016/j.ymgme.2008.06.014.

Anderson, Peter J, and Vincenzo Leuzzi. 2010. "White Matter Pathology in Phenylketonuria." Molecular Genetics and Metabolism 99 Suppl 1: S3-9. doi:10.1016/j.ymgme.2009.10.005.

Anderson, Peter J, Stephen J Wood, Dorothy E Francis, Lee Coleman, Vicki Anderson, and Avihu Boneh. 2007. "Are Neuropsychological Impairments in Children with Early-treated Phenylketonuria (PKU) Related to White Matter Abnormalities or Elevated Phenylalanine Levels?" Developmental Neuropsychology 32 (2): 645-668. doi:10.1080/87565640701375963.

Andolina, Diego, David Conversi, Simona Cabib, Antonio Trabalza, Rossella Ventura, Stefano Puglisi-Allegra, and Tiziana Pascucci. 2011. "5Hydroxytryptophan During Critical Postnatal Period Improves Cognitive Performances and Promotes Dendritic Spine Maturation in Genetic Mouse Model of Phenylketonuria." The International Journal of Neuropsychopharmacology 14 (4) (May): 479-489. doi:10.1017/S1461145710001288.

Antoshechkin, A G, T V Chentsova, Tatur VYu, D B Naritsin, and G P Railian. 1991. "Content of Phenylalanine, Tyrosine and Their Metabolites in CSF in Phenylketonuria." Journal of Inherited Metabolic Disease 14 (5): 749-754.

Babu, Ellappan, Yoshikatsu Kanai, Arthit Chairoungdua, Do Kyung Kim, Yuji Iribe, Sahatchai Tangtrongsup, Promsuk Jutabha, et al. 2003. "Identification of a Novel System L Amino Acid Transporter Structurally Distinct from Heterodimeric Amino Acid Transporters." J. Biol. Chem. 278 (44) (October 31): 43838-43845. doi:10.1074/jbc.M305221200.

Banerjee, Pia, Dorothy K Grange, Robert D Steiner, and Desirée A White. 2011. "Executive Strategic Processing During Verbal Fluency Performance in Children with Phenylketonuria." Child Neuropsychology: A Journal on Normal and Abnormal Development in Childhood and Adolescence 17 (2): 105-117. doi:10.1080/09297049.2010.525502.

Barretto, Junaura Rocha, Luciana Rodrigues Silva, Maria Efigênia Leite, Ney Boa-Sorte, Helena Pimentel, Antonio Conceição Purificação, Gildasio Carvalho, Maria Inês M M Fontes, and Tatiana Amorim. 2008. "Poor Zinc and Selenium Status in Phenylketonuric Children and Adolescents in 
Brazil." Nutrition Research (New York, N.Y.) 28 (3) (March): 208-211. doi:10.1016/j.nutres.2007.12.009.

Bevins, Rick A, and Joyce Besheer. 2006. "Object Recognition in Rats and Mice: a One-trial Non-matching-to-sample Learning Task to Study 'Recognition Memory'." Nature Protocols 1 (3) (October 12): 1306-1311. doi:10.1038/nprot.2006.205.

Bodoy, Susanna, Lorena Martín, Antonio Zorzano, Manuel Palacín, Raúl Estévez, and Joan Bertran. 2005. "Identification of LAT4, a Novel Amino Acid Transporter with System L Activity." Journal of Biological Chemistry 280 (12) (March 25): 12002 -12011. doi:10.1074/jbc.M408638200.

Bortolozzi, Analía, Ricardo Duffard, and Ana María Evangelista de Duffard. 2003. "Asymmetrical Development of the Monoamine Systems in 2,4dichlorophenoxyacetic Acid Treated Rats." Neurotoxicology 24 (1) (January): 149-157.

Brown, R E, D R Stevens, and H L Haas. 2001. "The Physiology of Brain Histamine." Progress in Neurobiology 63 (6) (April): 637-672.

Brumm, V L, D Bilder, and S E Waisbren. 2010. "Psychiatric Symptoms and Disorders in Phenylketonuria." Molecular Genetics and Metabolism 99 Suppl 1: S59-63. doi:10.1016/j.ymgme.2009.10.182.

Chishty, M., A. Reichel, N.J. Abbott, and D.J. Begley. 2002. "Sadenosylmethionine Is Substrate for Carrier Mediated Transport at the Blood-brain Barrier in Vitro." Brain Research 942 (1-2) (June): 46-50. doi:10.1016/S0006-8993(02)02654-9.

Christensen, H N, and J T Rothwell. 1948. "Association Between Rapid Growth and Elevated Cell Concentrations of Amino Acids; in Regenerating Liver After Partial Hepatectomy in the Rat." The Journal of Biological Chemistry 175 (1) (August): 101-105.

Colomé, Catrina, Rafael Artuch, Maria-Antònia Vilaseca, Cristina Sierra, Núria Brandi, Nilo Lambruschini, Francisco J Cambra, and Jaume Campistol. 2003. "Lipophilic Antioxidants in Patients with Phenylketonuria." The American Journal of Clinical Nutrition 77 (1) (January 1): 185-188.

de Groot, M J, M Hoeksma, N Blau, D J Reijngoud, and F J van Spronsen. 2010. "Pathogenesis of Cognitive Dysfunction in Phenylketonuria: Review of Hypotheses." Molecular Genetics and Metabolism 99 Suppl 1: S86-89. doi:10.1016/j.ymgme.2009.10.016.

Der Garabedian, P A, and J J Vermeersch. 1987. "Candida Lnorleucine,leucine:2-oxoglutarate Aminotransferase. Purification and Properties." European Journal of Biochemistry / FEBS 167 (1) (August 17): 141-147. 
Dokoupil, Katharina, Hulya Gokmen-Ozel, Anna Maria Lammardo, Kristina Motzfeldt, Martine Robert, Júlio César Rocha, Margreet van Rijn, Kirsten Ahring, Amaya Bélanger-Quintana, and Anita Macdonald. 2011. "Optimising Growth in Phenylketonuria: Current State of the Clinical Evidence Base." Clinical Nutrition (Edinburgh, Scotland) (September 27). doi:10.1016/j.clnu.2011.09.001. http://www.ncbi.nlm.nih.gov/pubmed/21959353.

Dotremont, H, B François, M Diels, and P Gillis. 1995a. "Nutritional Value of Essential Amino Acids in the Treatment of Adults with Phenylketonuria." Journal of Inherited Metabolic Disease 18 (2): 127-130.

Dyer, Charissa A. 1999. "Pathophysiology of Phenylketonuria." Mental Retardation and Developmental Disabilities Research Reviews 5 (2): 104112. doi:10.1002/(SICl)1098-2779(1999)5:2<104::AID-MRDD2>3.0.CO;27.

Enns, G M, R Koch, V Brumm, E Blakely, R Suter, and E Jurecki. 2010. "Suboptimal Outcomes in Patients with PKU Treated Early with Diet Alone: Revisiting the Evidence." Molecular Genetics and Metabolism 101 (2-3) (November): 99-109. doi:10.1016/j.ymgme.2010.05.017.

Erlandsen, H, and R C Stevens. 1999. "The Structural Basis of Phenylketonuria." Molecular Genetics and Metabolism 68 (2) (October): 103-125. doi:10.1006/mgme.1999.2922.

Følling, I. 1994. "The Discovery of Phenylketonuria." Acta Paediatrica (Oslo, Norway: 1992). Supplement 407 (December): 4-10.

Harding, Cary O. 2010. "New Era in Treatment for Phenylketonuria:

Pharmacologic Therapy with Sapropterin Dihydrochloride." Biologics:

Targets \& Therapy 4: 231-236.

Hörster, Friederike, Marina A Schwab, Sven W Sauer, Joachim Pietz, Georg F Hoffmann, Jürgen G Okun, Stefan Kölker, and Stefan Kins. 2006.

"Phenylalanine Reduces Synaptic Density in Mixed Cortical Cultures from Mice." Pediatric Research 59 (4 Pt 1) (April): 544-548.

doi:10.1203/01.pdr.0000203091.45988.8d.

Huttenlocher, P R. 2000. "The Neuropathology of Phenylketonuria: Human and Animal Studies." European Journal of Pediatrics 159 Suppl 2 (October): S102-106.

Hvas, A M, E Nexo, and J B Nielsen. 2006. "Vitamin B12 and Vitamin B6 Supplementation Is Needed Among Adults with Phenylketonuria (PKU)." Journal of Inherited Metabolic Disease 29 (1) (February): 47-53. doi:10.1007/s10545-006-0108-3. 
Joseph, Bernadin, and Charissa A Dyer. 2003. "Relationship Between Myelin Production and Dopamine Synthesis in the PKU Mouse Brain." Journal of Neurochemistry 86 (3) (August): 615-626.

Kanai, Yoshikatsu, Hiroko Segawa, Ken-ichi Miyamoto, Hiroshi Uchino, Eiji Takeda, and Hitoshi Endou. 1998. "Expression Cloning and Characterization of a Transporter for Large Neutral Amino Acids Activated by the Heavy Chain of 4F2 Antigen (CD98)." Journal of Biological Chemistry 273 (37): 23629 -23632. doi:10.1074/jbc.273.37.23629.

Kaufman, S. 1986. "Regulation of the Activity of Hepatic Phenylalanine Hydroxylase." Advances in Enzyme Regulation 25: 37-64.

Knudsen, G M, S Hasselbalch, P B Toft, E Christensen, O B Paulson, and H Lou. 1995. "Blood-brain Barrier Transport of Amino Acids in Healthy Controls and in Patients with Phenylketonuria." Journal of Inherited Metabolic Disease 18 (6): 653-664.

Koura, Hala M., Nagwa Abdallah Ismail, Ashraf F. Kamel, Azza M Ahmed, Amal Saad-Hussein, and Laila K. Effat. 2011. "A Long-term Study of Bone Mineral Density in Patients with Phenylketonuria Under Diet Therapy." Archives of Medical Science : AMS 7 (3) (June): 493-500. doi:10.5114/aoms.2011.23417.

Laclair, Caitlin E, Denise M Ney, Erin L MacLeod, and Mark R Etzel. 2009. "Purification and Use of Glycomacropeptide for Nutritional Management of Phenylketonuria." Journal of Food Science 74 (4) (July): E199-206. doi:10.1111/j.1750-3841.2009.01134.x.

Lee, Bor Jen, Ping Ting Lin, Yung Po Liaw, Sue Joan Chang, Chien Hsiung Cheng, and Yi Chia Huang. 2003. "Homocysteine and Risk of Coronary Artery Disease: Folate Is the Important Determinant of Plasma Homocysteine Concentration." Nutrition (Burbank, Los Angeles County, Calif.) 19 (7-8) (August): 577-583.

Lidsky, A S, M L Law, H G Morse, F T Kao, M Rabin, F H Ruddle, and S L Woo. 1985. "Regional Mapping of the Phenylalanine Hydroxylase Gene and the Phenylketonuria Locus in the Human Genome." Proceedings of the National Academy of Sciences of the United States of America 82 (18) (September): 6221-6225.

Lutz, P, H Schmidt, and U Batzler. 1990. "Study Design and Description of Patients." European Journal of Pediatrics 149 Suppl 1: S5-12.

Lutz, P, H Schmidt, G Frey, and H Bickel. 1982. "Standardized Loading Test with Protein for the Differentiation of Phenylketonuria from Hyperphenylalaninaemia." Journal of Inherited Metabolic Disease 5 (1): 29-35. 
Matalon, R, K Michals-Matalon, G Bhatia, E Grechanina, P Novikov, J D McDonald, J Grady, S K Tyring, and F Guttler. 2006. "Large Neutral Amino Acids in the Treatment of Phenylketonuria (PKU)." Journal of Inherited Metabolic Disease 29 (6) (December): 732-738. doi:10.1007/s10545-006-0395-8.

McDonald, J D, V C Bode, W F Dove, and A Shedlovsky. 1990. "Pahhph-5: a Mouse Mutant Deficient in Phenylalanine Hydroxylase." Proceedings of the National Academy of Sciences of the United States of America 87 (5) (March): 1965-1967.

McKean, C M, D E Boggs, and N A Peterson. 1968. "The Influence of High Phenylalanine and Tyrosine on the Concentrations of Essential Amino Acids in Brain." Journal of Neurochemistry 15 (3) (March): 235-241.

McKiernan, Patrick J. 2006. "Nitisinone in the Treatment of Hereditary Tyrosinaemia Type 1". Text. zotero://attachment/388/.

Michals-Matalon, Kimberlee, Gita Bhatia, Flemming Guttler, Stephen K Tyring, and Reuben Matalon. 2007. "Response of Phenylketonuria to Tetrahydrobiopterin." The Journal of Nutrition 137 (6 Suppl 1) (June): 1564S-1567S; discussion 1573S-1575S.

Muntau, Ania C, Wulf Röschinger, Matthias Habich, Hans Demmelmair, Björn Hoffmann, Christian P Sommerhoff, and Adelbert A Roscher. 2002. "Tetrahydrobiopterin as an Alternative Treatment for Mild Phenylketonuria." The New England Journal of Medicine 347 (26) (December 26): 2122-2132. doi:10.1056/NEJMoa021654.

Nakatani, Yasushi, Ikuko Sato-Suzuki, Naohisa Tsujino, Akane Nakasato, Yoshinari Seki, Masaki Fumoto, and Hideho Arita. 2008. "Augmented Brain 5-HT Crosses the Blood-brain Barrier Through the 5-HT Transporter in Rat." The European Journal of Neuroscience 27 (9) (May): 2466-2472. doi:10.1111/j.1460-9568.2008.06201.x.

Ney, Denise M, Angela K Hull, Sandra C van Calcar, Xiaowen Liu, and Mark R Etzel. 2008. "Dietary Glycomacropeptide Supports Growth and Reduces the Concentrations of Phenylalanine in Plasma and Brain in a Murine Model of Phenylketonuria." The Journal of Nutrition 138 (2) (February): 316-322.

$\mathrm{NIH}$ 2001. "National Institutes of Health Consensus Development Conference Statement: Phenylketonuria: Screening and Management, October 16-18, 2000." Pediatrics 108 (4) (October): 972-982.

Nishihira, T, T Takagi, and S Mori. 1993. "Amino Acid Imbalance and Intracellular Protein Synthesis." Nutrition (Burbank, Los Angeles County, Calif.) 9 (1) (February): 37-42. 
Ogawa, Shintaro, and Hiroshi Ichinose. 2006. "Effect of Metals and Phenylalanine on the Activity of Human Tryptophan Hydroxylase-2: Comparison with That on Tyrosine Hydroxylase Activity." Neuroscience Letters 401 (3) (July 3): 261-265. doi:10.1016/j.neulet.2006.03.031.

Ogburn, Kenyon D, Teodoro Bottiglieri, Zhiyou Wang, and Maria E FigueiredoPereira. 2006. "Prostaglandin J2 Reduces catechol-O-methyltransferase Activity and Enhances Dopamine Toxicity in Neuronal Cells."

Neurobiology of Disease 22 (2) (May): 294-301. doi:10.1016/j.nbd.2005.11.006.

Ouary, S, N Bizat, S Altairac, H Ménétrat, V Mittoux, F Condé, P Hantraye, and E Brouillet. 2000. "Major Strain Differences in Response to Chronic Systemic Administration of the Mitochondrial Toxin 3-nitropropionic Acid in Rats: Implications for Neuroprotection Studies." Neuroscience 97 (3): 521-530.

Pardridge, W M, and W H Oldendorf. 1975. "Kinetic Analysis of Blood-brain Barrier Transport of Amino Acids." Biochimica Et Biophysica Acta 401 (1) (August 5): 128-136.

Pascucci, Tiziana, Rossella Ventura, Stefano Puglisi-Allegra, and Simona Cabib. 2002. "Deficits in Brain Serotonin Synthesis in a Genetic Mouse Model of Phenylketonuria." Neuroreport 13 (18) (December 20): 2561-2564. doi:10.1097/01.wnr.0000047690.08940.39.

Pavon, Jorge Alex, and Paul F Fitzpatrick. 2006. "Insights into the Catalytic Mechanisms of Phenylalanine and Tryptophan Hydroxylase from Kinetic Isotope Effects on Aromatic Hydroxylation." Biochemistry 45 (36) (September 12): 11030-11037. doi:10.1021/bi0607554.

Pietz, J, R Kreis, A Rupp, E Mayatepek, D Rating, C Boesch, and H J Bremer. 1999. "Large Neutral Amino Acids Block Phenylalanine Transport into Brain Tissue in Patients with Phenylketonuria." The Journal of Clinical Investigation 103 (8) (April): 1169-1178. doi:10.1172/JCI5017.

Pietz, Joachim, André Rupp, Friedrich Ebinger, Dietz Rating, Ertan Mayatepek, Chris Boesch, and Roland Kreis. 2003. "Cerebral Energy Metabolism in Phenylketonuria: Findings by Quantitative In Vivo 31P MR Spectroscopy." Pediatric Research 53 (4) (April): 654-662. doi:10.1203/01.PDR.0000055867.83310.9E.

Puglisis-Allegra, Stefano, Simona Cabib, Tiziana Pascucci, Rossella Ventura, Francesco Cali, and Valentino Romano. 2000. "Dramatic Brain Aminergic Deficit in a Genetic Mouse Model of... : NeuroReport." Neurochemistry 11 (6): 1361-1364.

Reilly, C, J E Barrett, C M Patterson, U Tinggi, S L Latham, and A Marrinan. 1990. "Trace Element Nutrition Status and Dietary Intake of Children with 
Phenylketonuria." The American Journal of Clinical Nutrition 52 (1) (July): 159-165.

Richardson, S C, R A Aspbury, and M J Fisher. 1993. "The Role of Reversible Phosphorylation in the Hormonal Control of Phenylalanine Hydroxylase in Isolated Rat Proximal Kidney Tubules." Biochemical Journal 292 (Pt 2) (June 1): 419-424.

Rossier, Grégoire, Christian Meier, Christian Bauch, Vanessa Summa, Bernard Sordat, François Verrey, and Lukas C. Kühn. 1999. "LAT2, a New Basolateral 4F2hc/CD98-associated Amino Acid Transporter of Kidney and Intestine." Journal of Biological Chemistry 274 (49) (December 3): 34948 -34954. doi:10.1074/jbc.274.49.34948.

Schindeler, Suzanne, Suparna Ghosh-Jerath, Susan Thompson, Antonella Rocca, Pamela Joy, Allan Kemp, Caroline Rae, Kathryn Green, Bridget Wilcken, and John Christodoulou. 2007. "The Effects of Large Neutral Amino Acid Supplements in PKU: An MRS and Neuropsychological Study." Molecular Genetics and Metabolism 91 (1) (May): 48-54. doi:10.1016/j.ymgme.2007.02.002.

Schulpis, K H, G A Karikas, and E Papakonstantinou. 2002. "Homocysteine and Other Vascular Risk Factors in Patients with Phenylketonuria on a Diet." Acta Paediatrica (Oslo, Norway: 1992) 91 (8): 905-909.

Segawa, H, Y Fukasawa, K Miyamoto, E Takeda, H Endou, and Y Kanai. 1999. "Identification and Functional Characterization of a $\mathrm{Na}+$-independent Neutral Amino Acid Transporter with Broad Substrate Selectivity." The Journal of Biological Chemistry 274 (28) (July 9): 19745-19751.

Shefer, S, G S Tint, D Jean-Guillaume, E Daikhin, A Kendler, L B Nguyen, M Yudkoff, and C A Dyer. 2000a. "Is There a Relationship Between 3hydroxy-3-methylglutaryl Coenzyme a Reductase Activity and Forebrain Pathology in the PKU Mouse?" Journal of Neuroscience Research 61 (5) (September 1): 549-563.

Singer, Harvey S, Christina Morris, Colin Gause, Matthew Pollard, Andrew W Zimmerman, and Mikhail Pletnikov. 2009. "Prenatal Exposure to Antibodies from Mothers of Children with Autism Produces Neurobehavioral Alterations: A Pregnant Dam Mouse Model." Journal of Neuroimmunology 211 (1-2) (June 25): 39-48. doi:10.1016/j.jneuroim.2009.03.011.

Sitta, A, C S Vanzin, G B Biancini, V Manfredini, A B de Oliveira, C A Y Wayhs, G O S Ribas, et al. 2011. "Evidence That L-carnitine and Selenium Supplementation Reduces Oxidative Stress in Phenylketonuric Patients." Cellular and Molecular Neurobiology 31 (3) (April): 429-436. doi:10.1007/s10571-010-9636-3. 
Slocum, R.H., and J.G. Cummings. 1991. "Amino Acid Analysis of Physiological Samples." In Techniques in Diagnostic Human Biochemical Genetics, 87126. Wiley-Liss.

Smith, C B, and J Kang. 2000. "Cerebral Protein Synthesis in a Genetic Mouse Model of Phenylketonuria." Proceedings of the National Academy of Sciences of the United States of America 97 (20) (September 26): 1101411019.

Strauss, Kevin A, Bridget Wardley, Donna Robinson, Christine Hendrickson, Nicholas L Rider, Erik G Puffenberger, Diana Shellmer, Diana Shelmer, Ann B Moser, and D Holmes Morton. 2010. "Classical Maple Syrup Urine Disease and Brain Development: Principles of Management and Formula Design." Molecular Genetics and Metabolism 99 (4) (April): 333-345. doi:10.1016/j.ymgme.2009.12.007.

Tews, J K, and A E Harper. 1986. "Tissue Amino Acids in Rats Fed Norleucine, Norvaline, Homoarginine or Other Amino Acid Analogues." The Journal of Nutrition 116 (8) (August): 1464-1472.

Tews, J K, J J Repa, and A E Harper. 1990. "Norleucine: a Branched-chain Amino Acid Analog Affecting Feeding Behavior of Rats." Pharmacology, Biochemistry, and Behavior 35 (4) (April): 911-921.

Tews, J K, J J Repa, and A E Harper. 1991. "Branched-chain and Other Amino Acids in Tissues of Rats Fed Leucine-limiting Amino Acid Diets Containing Norleucine." The Journal of Nutrition 121 (3) (March): 364-378.

Tinggi, Ujang. 2008. "Selenium: Its Role as Antioxidant in Human Health." Environmental Health and Preventive Medicine 13 (2) (March 1): 102-108. doi:10.1007/s12199-007-0019-4.

Uchino, Hiroshi, Yoshikatsu Kanai, Do Kyung Kim, Michael F. Wempe, Arthit Chairoungdua, Emiko Morimoto, M. W. Anders, and Hitoshi Endou. 2002. "Transport of Amino Acid-Related Compounds Mediated by L-Type Amino Acid Transporter 1 (LAT1): Insights Into the Mechanisms of Substrate Recognition." Molecular Pharmacology 61 (4) (April 1): 729 -737. doi:10.1124/mol.61.4.729.

Uddén, Julia, Vasiliki Folia, and Karl Magnus Petersson. 2010. "The Neuropharmacology of Implicit Learning." Current Neuropharmacology 8 (4) (December): 367-381. doi:10.2174/157015910793358178.

UK PubMed Central (UKPMC). 1995. "The Value of Posttransplant Monitoring of Interleukin (IL)-2, IL-3, IL-4, IL-6, IL-8, and... - Abstract - UK PubMed Central". Journal Article. http://ukpmc.ac.uk/abstract/MED/7871561.

van Gool, Christel J.A.W, Adriana C van Houwelingen, and Gerard Hornstra. 2000. "The Essential Fatty Acid Status in Phenylketonuria Patients Under 
Treatment." The Journal of Nutritional Biochemistry 11 (11-12) (November): 543-547. doi:10.1016/S0955-2863(00)00111-X.

van Spronsen, F J, Marieke Hoeksma, and Dirk-Jan Reijngoud. 2009. "Brain Dysfunction in Phenylketonuria: Is Phenylalanine Toxicity the Only Possible Cause?" Journal of Inherited Metabolic Disease 32 (1) (February): 46-51. doi:10.1007/s10545-008-0946-2.

van Spronsen, Francjan J, Martijn J de Groot, Marieke Hoeksma, Dirk-Jan Reijngoud, and Margreet van Rijn. 2010. "Large Neutral Amino Acids in the Treatment of PKU: From Theory to Practice." Journal of Inherited Metabolic Disease 33 (6) (December): 671-676. doi:10.1007/s10545-0109216-1.

Verrey, François, Ellen I Closs, Carsten A Wagner, Manuel Palacin, Hitoshi Endou, and Yoshikatsu Kanai. 2004. "CATs and HATs: The SLC7 Family of Amino Acid Transporters." Pflügers Archiv: European Journal of Physiology 447 (5) (February): 532-542. doi:10.1007/s00424-003-1086-z.

Vogel, KR, FN Lambert, EA Arning, T Bottiglieri, and KM Gibson. 2012. "Therapeutic Efficacy of Competitive Non-physiological Amino Acid (NPAA) Intervention in Phenylketonuric Mice." Molecular Genetics and Metabolism 105 (3) (March): 114-115.

Wadhwani, K C, Q R Smith, and S I Rapoport. 1990. "Facilitated Transport of Lphenylalanine Across Blood-nerve Barrier of Rat Peripheral Nerve." The American Journal of Physiology 258 (6 Pt 2) (June): R1436-1444.

Waisbren, S, and D A White. 2010. "Screening for Cognitive and Socialemotional Problems in Individuals with PKU: Tools for Use in the Metabolic Clinic." Molecular Genetics and Metabolism 99 Suppl 1: S9699. doi:10.1016/j.ymgme.2009.10.006.

Williams, Robin A, Cyril DS Mamotte, and John R Burnett. 2008. "Phenylketonuria: An Inborn Error of Phenylalanine Metabolism." The Clinical Biochemist Reviews 29 (1) (February): 31-41.

Yanagida, Osamu, Yoshikatsu Kanai, Arthit Chairoungdua, Do Kyung Kim, Hiroko Segawa, Tomoko Nii, Seok Ho Cha, et al. 2001. "Human L-type Amino Acid Transporter 1 (LAT1): Characterization of Function and Expression in Tumor Cell Lines." Biochimica Et Biophysica Acta (BBA) Biomembranes 1514 (2) (October 1): 291-302. doi:10.1016/S00052736(01)00384-4.

Yoshida, S, Y Numachi, H Matsuoka, and M Sato. 2000. "The Absence of Impairment of Cliff Avoidance Reaction Induced by Subchronic Methamphetamine Treatment in Inbred Strains of Mice." The Tohoku Journal of Experimental Medicine 190 (3) (March): 205-212. 
Zagreda, L, J Goodman, D P Druin, D McDonald, and A Diamond. 1999. "Cognitive Deficits in a Genetic Mouse Model of the Most Common Biochemical Cause of Human Mental Retardation." The Journal of Neuroscience: The Official Journal of the Society for Neuroscience 19 (14) (July 15): 6175-6182.

Zinnanti, William J, and Jelena Lazovic. 2012. "Interrupting the Mechanisms of Brain Injury in a Model of Maple Syrup Urine Disease Encephalopathy." Journal of Inherited Metabolic Disease 35 (1) (January): 71-79. doi:10.1007/s10545-011-9333-5.

Zinnanti, William J., Jelena Lazovic, Kathleen Griffin, Kristen J. Skvorak, Harbhajan S. Paul, Gregg E. Homanics, Maria C. Bewley, Keith C. Cheng, Kathryn F. LaNoue, and John M. Flanagan. 2009. "Dual Mechanism of Brain Injury and Novel Treatment Strategy in Maple Syrup Urine Disease." Brain 132 (4) (April 1): 903 -918. doi:10.1093/brain/awp024. 